\title{
Article
}

\section{Orai1 Boosts SK3 Channel Activation}

\author{
Adéla Tiffner ${ }^{1}\left(\mathbb{D}\right.$, Valentina Hopl ${ }^{1}$, Romana Schober ${ }^{1,2}$, Matthias Sallinger ${ }^{1}$, Herwig Grabmayr ${ }^{1}(\mathbb{D}$, \\ Carmen Höglinger ${ }^{1}$, Marc Fahrner ${ }^{1}{ }^{\circledR}$, Victoria Lunz ${ }^{1}$, Lena Maltan ${ }^{1}{ }^{\circledR}$, Irene Frischauf ${ }^{1}{ }^{1},{ }^{1}$ Denis Krivic ${ }^{2}$,

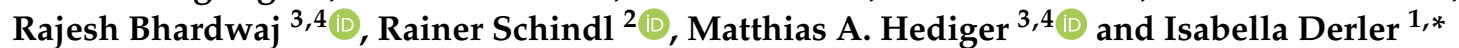

1 JKU Life Science Center, Institute of Biophysics, Johannes Kepler University Linz, A-4020 Linz, Austria; adela.tiffner@jku.at (A.T.); valentina.hopl@jku.at (V.H.); romana.schober@jku.at (R.S.); matthias.sallinger@jku.at (M.S.); herwig.grabmayr@jku.at (H.G.); carmen.hoeglinger@jku.at (C.H.); marc.fahrner@jku.at (M.F.); vici.lunz@gmx.at (V.L.); lena.maltan@jku.at (L.M.); irene.frischauf@jku.at (I.F.)

2 Gottfried Schatz Research Centre, Medical University of Graz, A-8010 Graz, Austria; denis.krivic@medunigraz.at (D.K.); rainer.schindl@medunigraz.at (R.S.)

3 Department of Nephrology and Hypertension, University of Bern, Inselspital, Freiburgstrasse 15, CH-3010 Bern, Switzerland; rajesh.bhardwaj@dbmr.unibe.ch (R.B.); matthias.hediger@ibmm.unibe.ch (M.A.H.)

4 Department of Biomedical Research, University of Bern, Inselspital, Freiburgstrasse 15, CH-3010 Bern, Switzerland

* Correspondence: isabella.derler@jku.at

Citation: Tiffner, A.; Hopl, V.; Schober, R.; Sallinger, M.; Grabmayr, H.; Höglinger, C.; Fahrner, M.; Lunz, V.; Maltan, L.; Frischauf, I.; et al. Orai1 Boosts SK3 Channel Activation. Cancers 2021, 13, 6357. https:// doi.org/10.3390/cancers13246357

Academic Editors: Juan A. Rosado and Tarik Smani

Received: 2 December 2021

Accepted: 13 December 2021

Published: 17 December 2021

Publisher's Note: MDPI stays neutral with regard to jurisdictional claims in published maps and institutional affiliations.

Copyright: (c) 2021 by the authors. Licensee MDPI, Basel, Switzerland. This article is an open access article distributed under the terms and conditions of the Creative Commons Attribution (CC BY) license (https:/ / creativecommons.org/licenses/by/ $4.0 /)$.
Simple Summary: Breast, colon, and prostate cancer account for about a third of cancer cases and a fifth of cancer deaths. At the molecular level, one reason for the development of cancer is the dysfunction or altered co-regulation of cellular proteins. In this study, we focused on the co-regulation of ion channels, specifically the prominent $\mathrm{Ca}^{2+}$ ion channel Orai1 and the $\mathrm{Ca}^{2+}$ activated $\mathrm{K}^{+}$ion channel SK3. It has recently been reported that their interplay promotes the growth of breast and colon cancer cells, but the molecular determinants for their co-regulation have remained elusive. In this study, we set out to characterize their interplay and the crucial regions therefore required. Moreover, we found that the function of prostate cancer cells is also controlled by the interplay of $\mathrm{Ca}^{2+}$ and the $\mathrm{Ca}^{2+}$ sensitive $\mathrm{K}^{+}$channels. Our findings provide a better understanding of the co-regulation of these ion channels, which could be used in the future for the development of novel therapeutics.

Abstract: The interplay of SK3, a $\mathrm{Ca}^{2+}$ sensitive $\mathrm{K}^{+}$ion channel, with Orai1, a $\mathrm{Ca}^{2+}$ ion channel, has been reported to increase cytosolic $\mathrm{Ca}^{2+}$ levels, thereby triggering proliferation of breast and colon cancer cells, although a molecular mechanism has remained elusive to date. We show in the current study, via heterologous protein expression, that Orai1 can enhance SK3 $\mathrm{K}^{+}$currents, in addition to constitutively bound calmodulin (CaM). At low cytosolic $\mathrm{Ca}^{2+}$ levels that decrease SK3 $\mathrm{K}^{+}$permeation, co-expressed Orai1 potentiates SK3 currents. This positive feedback mechanism of SK3 and Orai1 is enabled by their close co-localization. Remarkably, we discovered that loss of SK3 channel activity due to overexpressed CaM mutants could be restored by Orai1, likely via its interplay with the SK3-CaM binding site. Mapping for interaction sites within Orai1, we identified that the cytosolic strands and pore residues are critical for a functional communication with SK3. Moreover, STIM1 has a bimodal role in SK3-Orai1 regulation. Under physiological ionic conditions, STIM1 is able to impede SK3-Orai1 interplay by significantly decreasing their co-localization. Forced STIM1-Orai1 activity and associated $\mathrm{Ca}^{2+}$ influx promote $\mathrm{SK} 3 \mathrm{~K}^{+}$currents. The dynamic regulation of Orai1 to boost endogenous SK3 channels was also determined in the human prostate cancer cell line LNCaP.

Keywords: STIM1; Orai1; CRAC channel; $\mathrm{Ca}^{2+}$ activated $\mathrm{K}^{+}$ion channels; SK channels; SK3; calmodulin; LNCaP cells 


\section{Introduction}

Calcium $\left(\mathrm{Ca}^{2+}\right)$ ionsplay a variety of critical roles in many vital aspects of cellular life. $\mathrm{Ca}^{2+}$ signaling triggers short- and long-term cellular processes responsible for fundamental physiological functions, including secretion, gene regulation, muscle contraction, activation of the immune system, cell proliferation, cell motility, and apoptosis [1-7]. Defects in the cellular $\mathrm{Ca}^{2+}$ homeostasis due to dysfunction or changes in $\mathrm{Ca}^{2+}$ signal transduction can lead to severe immune deficiencies, neurological diseases, cardiovascular problems, and various types of cancers [8]. $\mathrm{Ca}^{2+}$ enters the cell via diverse $\mathrm{Ca}^{2+}$ ion channels. The resulting elevations of intracellular $\mathrm{Ca}^{2+}$ levels can regulate the activity of $\mathrm{Ca}^{2+}$ sensing ion channels. Several reports have already provided evidence of an interplay of $\mathrm{Ca}^{2+}$ and $\mathrm{Ca}^{2+}$ regulated potassium $\left(\mathrm{K}^{+}\right)$ion channels such as $\mathrm{Ca}_{\mathrm{V}} 2.3$ with BK channels [9], Orai1 with the ether a-gogo $\mathrm{K}^{+}$channel hEag1 [10] or BK channels [11,12], Orai1 [13], or TRPV6 [14] with the small conductance $\mathrm{Ca}^{2+}$-activated activated $\mathrm{K}^{+}$channels SK4 and Orai1 with its homolog SK3 [13,15-19]. The interplay of the $\mathrm{Ca}^{2+}$ ion channel Orai1 with the $\mathrm{Ca}^{2+}$-activated $\mathrm{K}^{+}$ion channel SK3 is currently best studied in breast cancer cells $[16,20,21]$.

Orai1 $[22,23]$ together with the ER-localized $\mathrm{Ca}^{2+}$ sensor STIM1 [24-26] constitute the so-called $\mathrm{Ca}^{2+}$ release-activated $\mathrm{Ca}^{2+}(\mathrm{CRAC})$ channel. CRAC channels are activated upon ER $\mathrm{Ca}^{2+}$ store depletion [22,27]. In response to the drop of $\mathrm{ER} \mathrm{Ca}^{2+}$ concentration, STIM1 undergoes a conformational change [25,28-32], coupling to and activating Orai1 to allow $\mathrm{Ca}^{2+}$ influx [33-36]. STIM1 induced Orai1 activation is only guaranteed as long as the cytosolic $\mathrm{N}$ - and C-terminus, as well as the loop2 region of this $\mathrm{Ca}^{2+}$ ion channel, are intact [30,37-46]. STIM1-Orai1 coupling, predominantly established via the main coupling site at the Orai1 C-terminus, can be disrupted via either a single point mutation L273D or C-terminal truncations to L276 or beyond $[35,38,47,48]$. N-terminal truncations and site-directed mutagenesis revealed that residues downstream of Q72 are indispensable for full activation of STIM1 mediated $\mathrm{Ca}^{2+}$ entry [37,38,47]. The residues 39-59 of the Orai1 N-terminus associate with the A-kinase anchoring protein (AKAP79) that binds both calcineurin and nuclear factor of activated T-cells (NFAT). Orai1-AKAP79 association thus allows local calcineurin activation and rapid NFAT nuclear translocation in response to local $\mathrm{Ca}^{2+}$ entry through Orai1 [49].

SK3 channels are part of the SK channel family consisting of the small (SK1, SK2, and SK3) and intermediate (SK4) conductance $\mathrm{Ca}^{2+}$-activated $\mathrm{K}^{+}$channels. The pore forming $\alpha$ subunits of SK channels consist of a tetrameric six-transmembrane domain (S1-S6) structure flanked by the cytosolic N- and C-terminal strands. The S4-S5 linker in the SK channel contains two $\alpha$-helices, $\mathrm{S}_{45} \mathrm{~A}$, and $\mathrm{S}_{45} \mathrm{~B}$. The $\mathrm{SK}$ channel gating is triggered by changes in intracellular $\mathrm{Ca}^{2+}$ concentrations at the submicromolar level $\left(\mathrm{K}_{\mathrm{D}}=0.5 \mu \mathrm{M}\right)$ [50] via bound calmodulin $(\mathrm{CaM})$ and occurs in a voltage-independent manner $[51,52]$. On the basis of the structural and functional analyses, Lee et al. [53] presented the $\mathrm{Ca}^{2+}$-dependent channel opening mechanism of SK4. The high structural similarity between SK3 and SK4 suggests that, in analogy to SK4, similar $\mathrm{Ca}^{2+}$-dependent pore opening mechanisms exist for SK3. As shown by Lee et al. [53], four CaM molecules bind to each channel tetramer. The C-terminal lobe of CaM is constitutively bound to SK4 while the N-terminal lobe binds SK4 in a $\mathrm{Ca}^{2+}$ dependent manner, thereby controlling channel opening. Elevations of intracellular $\mathrm{Ca}^{2+}$ levels allow $\mathrm{Ca}^{2+}$ binding to the CaM N-lobe, triggering a conformational change of the S4-S5 linker, which results in pore opening $[50,53] . \mathrm{Ca}^{2+}$ independent $\mathrm{CaM}$ binding has been further reported to regulate SK2 channel trafficking to the membrane [54].

The structure-function relationship of Orai1 and SK3 is currently well understood.

Recent studies have reported the co-localization of the SK3 and Orai1 channels in breast and colon cancer cells $[13,16,18,19,55-57]$. There, these channels control cell proliferation and migration or trigger bone metastasis $[15,16,19,56,58,59]$, as found, for example, for SK3-Orai1 complexes in breast cancer cells [56]. While normal human breast and colon cancer cells contain only Orai1, the corresponding cancer cells express SK3 and Orai1 co-localized in lipid rafts [16]. Those cells exhibit constitutive Orai1-dependent $\mathrm{Ca}^{2+}$ entry, independent of STIM1, which is promoted via hyperpolarization due to SK3 
channel activation. This has led to the assumption that Orai1-induced SK3 activation is mediated via direct or indirect interaction of those two proteins, potentially inducing structural changes to open the Orai pore subsequently, leading to the constitutive activity of the channel [57]. Indeed, there is evidence for a co-regulation of SK3 and Orai1 in breast [17] and colon $[14,16,19,60]$ cancer cells. However, the structural requirements and key determinants manifesting their interplay are still unknown.

Here, we present crucial, previously elusive conditions that mediate the communication between the SK3 and Orai1 channels. We show that Orai1 promotes SK3 $\mathrm{K}^{+}$currents and restores SK3 channel activity, which has been abolished by CaM mutants. Using a set of point and truncation mutants in Orai1, we uncovered that an intact pore geometry and virtually the entire Orai1 N- and C-termini are crucial for the SK3-Orai1 interplay. While the SK3-Orai1 co-regulation occurs independently of STIM1, STIM1 is able to reduce the extent of SK3-Orai1 co-localization, and thus their interplay under physiological conditions. The SK3-Orai1 co-regulation occurs not only in the standard HEK 293 expression system, but also in the human prostate cancer cell line, LNCaP.

\section{Materials and Methods}

2.1. Reagents

Inhibitors (NS8593 hydrochloride Cat \#: N-195, 4-AP Cat \#: A-115) and activators (NS-309 Cat \#: N-180, 1-EBIO Cat \#: E-150, Cyppa Cat \#: C-110) were purchased from Alomone Labs (Jerusalem, Israel).

\subsection{Molecular Biology}

For N-terminal fluorescence labeling of human Orai1 (Orai1; Accession number NM_032790, kindly provided by A. Rao's lab (Center for Autoimmunity and Inflammation, La Jolla Institute for Immunology, UC San Diego's Research Park, San Diego, CA, USA), the constructs were cloned into the pEYFP-C1 (Clontech Laboratories, Inc. (since 2015 Takara Bio USA, Inc. San Jose, CA, USA)) expression vector via KpnI and XbaI (Orai1) restriction sites, respectively. Orai1 N-terminal deletion mutants amplified via PCR including a $5^{\prime} \mathrm{KpnI}$ and a $3^{\prime} \mathrm{XbaI}$ restriction site for cloning into the $\mathrm{pEYFP-C1}$ vector as described in [33]. Site-directed mutagenesis of Orai1 was performed using the QuikChange ${ }^{\mathrm{TM}} \mathrm{XL}$ site-directed mutagenesis kit (Stratagene (since 2007 Agilent Technologies, Inc., San Diego, CA, USA) with the corresponding Orail constructs serving as a template according to [53].

For N-terminal fluorescence labeling of human SK3 (SK3; Accession number AAP45947.1, kindly provided by N. Marrion's lab (School of Physiology, Pharmacology \& Neuroscience, University of Bristol, Bristol, England), the constructs were cloned into the pEYFP-C1 (Clontech Laboratories, Inc.) expression vector via EcoRI and BamHI (SK3) restriction sites, respectively.

Human STIM1 (STIM1; Accession number: NM_003156) N-terminally ECFP-tagged was kindly provided by T. Meyer's Lab (Chemical and Systems Biology, Stanford University, Stanford, CA, USA).

CaM was amplified by PCR and cloned into YFP-/CFP-C1 vectors using EcoRI and SacII. Frame correction was performed at the beginning of the MCS, leading to a frame equivalent to YFP-/CFP-C2 vectors.

The CaM mutant (CaMMUT) has mutations introduced on all four EF hands, rendering it insensitive to $\mathrm{Ca}^{2+}$. Point mutations within CaM have been performed using the QuikChange $^{\mathrm{TM}} \mathrm{XL}$ site-directed mutagenesis kit (Stratagene).

All clones were confirmed by sequence analysis.

\subsubsection{Generation of STIM1/Orai1 Double Knockout HEK 293 Cells Using CRISPR/Cas9} Genome Editing

The guide RNA pairs within exon 1 of STIM1 were identified using the Benchling CRISPR webtool (https://benchling.com/crispr, accessed on 12 October 2015) and the following complementary oligos with BbsI compatible overhangs were designed: 
STIM1_gRNA1 for: 5'-CAC CGT TCT GTG CCC GCG GAG ACT C-3'

STIM1_gRNA1 rev: 5'-AAA CGA GTC TCC GCG GGC ACA GAA C-3'

STIM1_gRNA2 for: $5^{\prime}$-CAC CGT ATG CGT CCG TCT TGC CCT G-3'

STIM1_gRNA2 rev: 5'-AAA CCA GGG CAA GAC GGA CGC ATA C-3'

The oligo pairs were annealed by incubating for $5 \mathrm{~min}$ at $95^{\circ} \mathrm{C}$ in a thermocycler and then ramping down to $25^{\circ} \mathrm{C}$ at $5{ }^{\circ} \mathrm{C} / \mathrm{min}$. The dsDNA guide inserts were ligated into BbsI-digested pX330-PGK-puro vector. HEK 293 cells seeded in a 6-well plate were co-transfected with $1 \mu \mathrm{g}$ of each plasmid using Lipofectamine ${ }^{\circledR} 3000$ (Thermo Fisher Scientific, Waltham, MA, USA) when the cells were $50-60 \%$ confluent. The transfectants were subjected to $96 \mathrm{~h}$ of puromycin selection $(1.5 \mu \mathrm{g} / \mathrm{mL}), 24 \mathrm{~h}$ after transfection. For further knockout of Orai1, the guide RNA pairs within exon 2 and exon 3 were identified using the Benchling CRISPR webtool and the following complementary oligos with BbsI compatible overhangs were designed:

Exon 2:

Orai1_gRNA1 for: 5'-CACCGATCGGCCAGAGTTACTCCG-3'

Orai1_gRNA1 rev: 5'-AAACCGGAGTAACTCTGGCCGATC-3'

Exon3:

Orai1_gRNA2 for: 5'-CACCGGCGGAGTTTGCCCGCTTAC-3' Orai1_gRNA2 rev: 5'-AAACGTAAGCGGGCAAACTCCGCC-3'

The oligo pairs were annealed as mentioned above. The dsDNA guide inserts with BbsI overhangs were ligated into BbsI-digested pU6-(BbsI) CBh-Cas9-T2 A-mCherry (Addgene (Watertown, MA, USA) Plasmid \#64324). The resulting constructs were cotransfected in HEK 293 STIM1 KO cells seeded in a T25 flask using Lipofectamine 2000. The transfected cells were FACS-sorted with mCherry fluorescence, and single cells were seeded in a 96-well plate. The cells were tested by $\mathrm{Ca}^{2+}$ imaging with FURA-2 and a singlecell-derived clone was functionally confirmed to have undergone knockout of STIM1 and Orai1. Cells were used until passage 18.

\subsubsection{Western Blot Analysis and Co-Immunoprecipitation}

Untransfected as well as transfected (transfection 16-24 h prior to lysis) wild-type or CRISPR/Cas9 STIM1/Orai1 double knockout (STIM1/Orai1 DKO) HEK 293 cells were cultured in $12 \mathrm{~cm}$ dishes, harvested, and washed twice in an HBSS (Hank's balanced salt solution) buffer containing $1 \mathrm{mM}$ EDTA. After centrifugation $(1000 \times \mathrm{g} / 2 \mathrm{~min})$, cell pellets were resuspended in homogenization buffer $(25 \mathrm{mM}$ Tris $\mathrm{HCl} \mathrm{pH} \mathrm{7.4,50} \mathrm{mM} \mathrm{NaCl}$, protease inhibitor (Roche, Basel, Switzerland)) and incubated on ice for $15 \mathrm{~min}$. Lysed cells were passed 10 times through a $27 \mathrm{G} \frac{1}{2}$ " needle and centrifuged at $1000 \times g$ for $10 \mathrm{~min}$ at $4{ }^{\circ} \mathrm{C}$ to pellet debris. Then, $21 \mu \mathrm{L}$ of each sample was mixed with nonreducing Laemmli's buffer, heated for $10 \mathrm{~min}$ at $55{ }^{\circ} \mathrm{C}$, and subjected to 3-8\% Tris-acetate gels (BioRad, Vienna, Austria). Samples were loaded on a $12 \%$ SDS page, transferred to a nitrocellulose membrane, and immunoblotted with suitable antibodies (antiSK3 antibodies (Alomone labs), antiSTIM1 (CellSignaling, Frankfurt am Main, Germany), antiOrai1, antirabbit, and antiActin (SigmaAldrich, Taufkirchen, Germany)).

For co-immunoprecipitation, detached cells were incubated in lysis buffer for $2 \mathrm{~h}$ on ice with constant shaking. After centrifugation $(1000 \times g, 10 \mathrm{~min})$ and collecting the supernatant, $3 \mu \mathrm{g}$ of anti-Orai1 or anti-STIM1 antibodies were added and shaken at $4{ }^{\circ} \mathrm{C}$ over night. On the next day, $100 \mu \mathrm{L}$ Sepharose A beads were added and incubated for $2 \mathrm{~h}$ at $4{ }^{\circ} \mathrm{C}$ with constant shaking. Samples were centrifuged for $10 \mathrm{~s}$ at maximum speed and beads washed $3 \times$ with ice cold lysis buffer. $50 \mu \mathrm{L}$ of $2 \times$ Laemmli buffer were added to the beads and boiled for $5 \mathrm{~min}$ at $95^{\circ} \mathrm{C}$. Samples were then loaded on a $12 \%$ SDS PAGE, blotted, and detected with an anti-SK3 antibody (Alomone labs). A Precision Plus Dual Color standard was used for size comparison (BioRad).

Each experiment was performed at least 3 independent times. 


\subsection{Cell Culture and Transfection}

The transient transfection of HEK 293 or STIM1/Orai1 DKO HEK 293 cells was performed [61] using the TransFectin Lipid Reagent (BioRad) with the corresponding plasmids. The transient transfection of passages 3-5 of LNCaP cells was performed using the Lipofectamine ${ }^{\circledR} 3000$ transfection Reagent (Thermo Fisher Scientific) with the corresponding plasmids. Measurements were carried out $24 \mathrm{~h}$ following transfection. Notably, all LNCaP cell experiments described here were feasible only within the cell passages 3-5. Earlier and later passages failed to reveal SK3 channel activation (see Section 3.6) upon the same solution conditions.

\subsection{Electrophysiology}

Electrophysiological recordings that assessed the characteristics of 2-3 constructs were carried out in paired comparison on the same day. Expression patterns and levels of the various constructs were carefully monitored by confocal fluorescence microscopy and were not significantly changed by the introduced mutations. Electrophysiological experiments were performed at $20-24{ }^{\circ} \mathrm{C}$, using the patch-clamp technique in the wholecell recording configuration. For SK3/Orai1 current measurements, voltage ramps were usually applied every $5 \mathrm{~s}$ from a holding potential of $0 \mathrm{mV}$, covering a range of -90 to $+90 \mathrm{mV}$ over $1 \mathrm{~s}$. Used solution conditions to characterize STIM1/Orai1 and SK3 currents individually, but also in their interplay, are systematically summarized in Appendix A. The two main solution conditions applied are Physiological SK3 Solution Conditions with $[\text { EGTA }]_{\text {intra }}$ and Symmetrical SK3 Solution Conditions with [EGTA $]_{\text {intra }}$. They share the same intracellular pipette solution but differ in the composition of the extracellular solution. The internal pipette solution contained (in $\mathrm{mM}$ ) $144 \mathrm{KCl}, 1.49 \mathrm{MgCl}_{2}, 10 \mathrm{HEPES}$, and 0.1 EGTA (or 0.1 BAPTA). The physiological extracellular solution consisted of (in $\mathrm{mM}) 140 \mathrm{NaCl}, 5 \mathrm{KCl}, 1 \mathrm{MgCl}_{2}, 10 \mathrm{HEPES}, 10$ glucose, and $2 \mathrm{CaCl}_{2}$, with a $\mathrm{pH}$ of 7.4 . The corresponding symmetrical extracellular solution consisted of (in $\mathrm{mM}$ ) $144 \mathrm{KCl}, 1$ $\mathrm{MgCl}_{2}, 10$ HEPES, 10 glucose, and $10 \mathrm{CaCl}_{2}$, with a $\mathrm{pH}$ of 7.4. The currents recorded under physiological solution conditions were obtained at $+30 \mathrm{mV}$, while the ones recorded under symmetrical solution conditions were obtained at $-74 \mathrm{mV}$. Furthermore, Orai1 $\mathrm{Ca}^{2+}$ currents were obtained at $-74 \mathrm{mV}$. The $\mathrm{Na}^{+}$-DVF solution contained $150 \mathrm{mM} \mathrm{NaCl}, 10 \mathrm{mM}$ HEPES, $10 \mathrm{mM}$ glucose, and $10 \mathrm{mM}$ EDTA, with a $\mathrm{pH}$ of 7.4. Applied voltages were not corrected for the liquid junction potential, which was determined as $+12 \mathrm{mV}$. Experiments were performed using HEK 293 cells, STIM1/Orai1 DKO HEK 293 cells, or LNCaP cells as indicated.

\subsection{Confocal Fluorescence Microscopy}

Confocal FRET microscopy was performed on normal HEK 293 or CRISPR/Cas9 STIM1/Orai1 double knockout (STIM1/Orai1-DKO) HEK 293 cells. The transfected cells were grown on coverslips for $24 \mathrm{~h}$ and subsequently transferred to an extracellular solution consisting of $140 \mathrm{mM} \mathrm{NaCl}, 5 \mathrm{mM} \mathrm{KCl}, 1 \mathrm{mM} \mathrm{MgCl}_{2}, 2 \mathrm{mM} \mathrm{CaCl}_{2}, 10 \mathrm{mM}$ glucose, and 10 mM HEPES buffer (adjusted to $\mathrm{pH} 7.4$ with $\mathrm{NaOH}$ ). The experimental setup consisted of a CSU-X1 Real-Time Confocal System (Yokogawa Electric Corporation, Musashino, Tokyo, Japan) combined with two CoolSNAP HQ2 CCD cameras (Photometrics, Tucson, AZ, USA). The installation was also fitted with a dual port adapter (dichroic, 505lp; cyan emission filter, 470/24; yellow emission filter, 535/30; Chroma Technology Corporation, Olching, Germany). An Axio Observer.Z1 inverted microscope (Carl Zeiss, Oberkochen, Germany) and two diode lasers (445 and 515 nm, Visitron Systems, Puchheim, Germany) were connected to the described configuration. All described components were positioned on a Vision IsoStation antivibration table (Newport Corporation, Irvine, CA, USA). Image recording and control of the confocal system were carried out with the VisiView software package (v.2.1.4, Visitron Systems). Cross-excitation and spectral bleed-through necessitate image correction before any FRET calculation. Cross-excitation calibration factors were therefore determined for all expressed DNA constructs on each measurement day. After 
threshold determination as well as background signal subtraction, the apparent FRET efficiency Eapp was calculated on a pixel-to-pixel basis. This was performed with a custom program48 integrated into MATLAB (v.7.11.0, The MathWorks, Inc., Natick, MA, USA) that implements a microscope-specific constant $\mathrm{G}$ parameter of 2.75.

Fluorescence images of the subcellular localization of NFAT transcription factors in HEK 293 cells were recorded using a QLC100 Real-Time Confocal System (VisiTech Int., Sunderland, UK) connected to two Photometrics CoolSNAPHQ monochrome cameras (Roper Scientific, Planegg, Germany) and a dual-port adapter (dichroic: 505lp; cyan emission filter: 485/30; yellow emission filter: 535/50; Chroma Technology Corp., Olching, Germany). This system was attached to an Axiovert 200M microscope (Zeiss, Oberkochen, Germany) in conjunction with two diode lasers (445 nm, $515 \mathrm{~nm}$ ) (Visitron Systems, Puchheim, Germany). Visiview 2.1.1 software (Visitron Systems) was used for image acquisition and control of the confocal system. ImageJ was employed for subcellular localization analysis of the transcription factors by means of intensity measurements of the cytosol and nucleus, distinguishing between three different populations with different nucleus/cytosol ratios: inactive $(<0.85)$, homogenous $(0.85-1.15)$, and active $(>1.15)$.

\subsection{Fluorescence-Based $\mathrm{Ca}^{2+}$ Imaging}

STIM1/Orai1 DKO HEK 293 cells were loaded with $1 \mathrm{mM}$ Fura-2 AM for 20 min at $37^{\circ} \mathrm{C}$ in Ringer solution containing $145 \mathrm{mM} \mathrm{NaCl}, 5 \mathrm{mM} \mathrm{KCl}, 10 \mathrm{mM}$ glucose, $10 \mathrm{mM}$ HEPES, and $1 \mathrm{mM} \mathrm{MgCl}^{+}, 2 \mathrm{mM} \mathrm{CaCl}$ for $2 \mathrm{mM} \mathrm{Ca}^{2+}$. The cells were then washed three times, and the coverslips were mounted on an Axiovert 135 inverted microscope (ZEISS, Oberkochen, Germany), where fluorescence was recorded from individual cells, with excitation wavelengths of 340 and $380 \mathrm{~nm}$ and emission wavelength at $505 \mathrm{~nm}$. Changes in $\mathrm{Ca}^{2+}$ were monitored using the Fura-2 340/380 fluorescence ratio and calibrated according to the method established by Grynkiewicz et al. [48]. The fluorescence microscope was equipped with a monochromator (T.I.L.L. Photonics, Kaufbeuren, Germany) and corresponding filter sets and allowed the detection of CFP/YFP/red fluorescent protein fluorescence.

\subsection{Co-Localization Analysis}

The same technical equipment as for confocal FRET microscopy was used. Colocalization analysis was carried out when images of a co-expression indicated that two proteins were localized at the same positions (pixel-by-pixel analysis, orange in the CFP/YFP overlay image). The Pearson correlation coefficient ( $R$-value) was used to quantify the strength of the co-localization, where a value of $R=1$ signifies perfect positive correlation/co-localization.

\subsection{Cell Proliferation Assay}

Cells were seeded at an initial density of $1.5 \times 10^{4}$ cells/well in 24 -well plates (ThermoFisher). Cells were incubated for 4 days in a medium (control) or with a medium, containing agonists (NS309, Cyppa) or antagonists (NS8593 hydrochloride, 4-AP, $\mathrm{La}^{3+}$, Synta66, GSK7975A, BTP2) of the SK3 channel or Orai1 channel at various concentrations, respectively. The CellTiter $96^{\circledR}$ AQueous Non-Radioactive Cell Proliferation Assay kit commercially available (Promega, Walldorf, Germany), containing MTS solution (tetrazolium compound) and PMS solution (electron coupling reagent), was used to calculate the cell growth upon different conditions. Cells treated with MTS/PMS solution were equilibrated for $4 \mathrm{~h}$ at $37^{\circ} \mathrm{C}$ incubator before the measurement of absorption at $490 \mathrm{~nm}$ by plate reader Zenyth3100 was executed. Every measurement was performed in triplicate.

\subsection{Statistics}

All data are presented as the mean \pm SEM (standard error of the mean) for the indicated number of experiments. Statistical significance was determined by Mann-Whitney test for comparison of two groups (using Origin Pro 2019, Northampton, MA, USA). Statistical significance was set to $p<0.05$ and is indicated in the bar diagrams with an asterisk $\left(^{*}\right)$. 


\section{Results}

\subsection{Mild Cytosolic Ca ${ }^{2+}$ Buffering Allows Robust SK3 Channel Activation and Weak} STIM1-Orai1 Activation

Previous reports on breast and colon cancer cells revealed enhanced $\mathrm{Ca}^{2+}$ levels due to an interplay of SK3 and Orai1, independent of STIM1 [16,17]. Prior to our investigations of a potential co-regulation of SK3 and Orai1 channels in HEK 293 cells, we systematically examined individual SK3 and STIM1-Orai1 current activation upon their heterologous expression, using distinct solution conditions, differing mainly in intracellular $\mathrm{Ca}^{2+}$ and/or EGTA concentration. The detailed solution compositions used are highlighted by italics/underscore and summarized in Appendix A. Our goal was to confirm the $\mathrm{Ca}^{2+}$ sensitivity of SK3 channels and to reach intracellular $\mathrm{Ca}^{2+}$ concentrations, which still allow the activation of SK3 currents, but leave STIM1 and Orai1 in the resting or marginally active state.

As shown in previous reports [62-64], we confirmed via electrophysiological experiments that SK3 $\mathrm{K}^{+}$currents enhance with increasing intracellular $\mathrm{Ca}^{2+}$ concentrations. For this purpose, we used both symmetrical and physiological solution conditions with the pipette solution containing progressively increasing buffered $\mathrm{Ca}^{2+}$ concentrations $(50,100$, 250, 350, 600, 800, and $1000 \mathrm{nM}$; symmetrical or physiological SK3 solution conditions with buffered $\left.\left[\mathrm{Ca}^{2+}\right]_{\text {intra }}\right)$. SK3 evoked $\mathrm{K}^{+}$currents, as determined using repetitive voltage-ramps from -90 to $+90 \mathrm{mV}$, exhibited under symmetrical SK3 $\mathrm{K}^{+}$solution conditions a double rectifying I/V relationship and a reversal potential of $\sim 0 \mathrm{mV}$ [62-64] (Figure S1A,B). Under physiological SK3 $\mathrm{K}^{+}$solution conditions, SK3 currents displayed an outward rectifying current with a reversal potential of $\sim-70 \mathrm{mV}$, in accord with Xia et al. [64] (Figure S1D,E). Under both conditions, increasing $\mathrm{Ca}^{2+}$ concentrations in the pipette solution resulted in enhanced SK3 mediated $\mathrm{K}^{+}$currents (Figure S1C,F).

Additionally, we revealed via varying EGTA concentrations in the pipette solution (symmetrical or physiological SK3 solution conditions with [EGTA] $]_{\text {intra }}$ ) that $100 \mu \mathrm{M}$ EGTA enabled the activation of SK3 mediated $\mathrm{K}^{+}$currents (Figures $1 \mathrm{~A}-\mathrm{C}$ and $\mathrm{S} 2 \mathrm{~A}-\mathrm{C}$ ). SK3 $\mathrm{K}^{+}$ currents exhibited upon whole-cell break-in slight constitutive activity, which reached a steady-state level after $\sim 250 \mathrm{~s}$, as determined from repetitive voltage-ramps at voltages with highest currents reached $(-74 \mathrm{mV}$ for symmetrical and $+30 \mathrm{mV}$ for physiological solution conditions; Figures $1 \mathrm{~A}-\mathrm{C}$ and S2A-C). Higher EGTA concentrations in the pipette solution, which decrease intracellular $\mathrm{Ca}^{2+}$ concentrations, strongly reduced (200 $\mu \mathrm{M}$ EGTA) or abolished (>200 $\mu \mathrm{M}$ EGTA) SK3 $\mathrm{K}^{+}$current activation (Figures $1 \mathrm{~A}-\mathrm{C}$ and S2A-C). Thus, cytosolic $\mathrm{Ca}^{2+}$ levels reached with $100 \mu \mathrm{M}$ EGTA appear to be sufficient for SK3 channel activation, while higher EGTA buffers decreased cytosolic $\mathrm{Ca}^{2+}$ too much to allow SK3 activation. The I/V relationships obtained using $100 \mu \mathrm{M}$ EGTA for both, physiological as well as symmetrical solutions, are comparable to those obtained with increasing intracellular $\mathrm{Ca}^{2+}$ concentrations (symmetrical or physiological SK3 solution conditions with buffered $\left[\mathrm{Ca}^{2+}\right]_{\text {intra }}$; Figures $1 \mathrm{C}$ and S2C). 

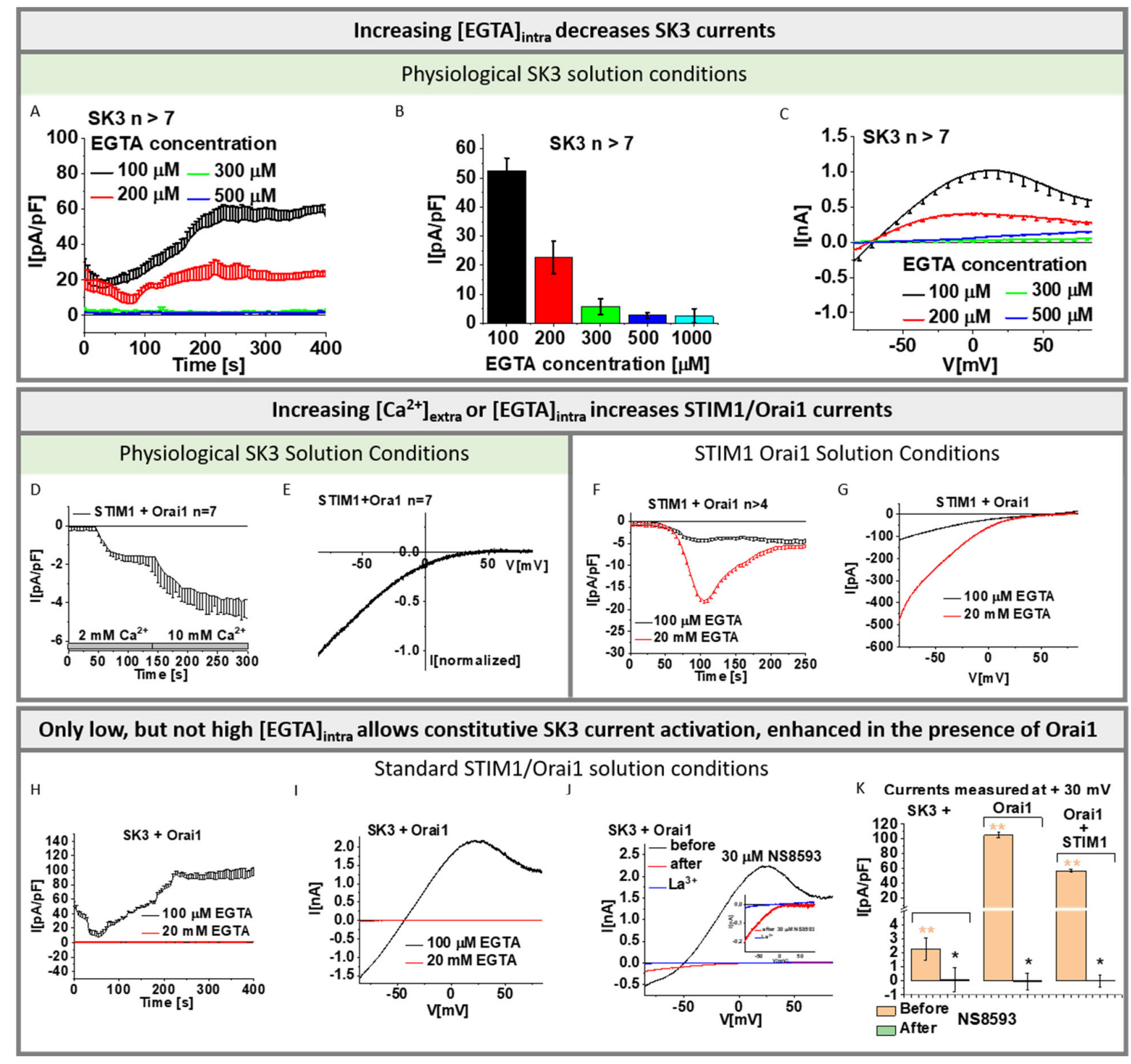

Figure 1. Characterization of SK3 and STIM1/Orai1 channel currents. (A) Time course of SK3 mediated whole-cell outward $\mathrm{K}^{+}$currents at $+30 \mathrm{mV}$ using physiological solution conditions and recorded in the presence of different EGTA concentration in the pipette solution; (B) Block diagram depicts maximum current densities measured in (A); (C) Currentvoltage relationship (I/V) corresponding to (B); (D) Time course of whole-cell inward currents at $-74 \mathrm{mV}$ of Orai1 in co-expression with STIM1 under physiological solution conditions. Inward currents activated upon passive store-depletion via $100 \mu \mathrm{M}$ EGTA are shown in $2 \mathrm{mM}$ followed by $10 \mathrm{mM}$ extracellular $\mathrm{Ca}^{2+}$ solution; (E) I/V relationships corresponding to (D) in $10 \mathrm{mM}$ extracellular $\mathrm{Ca}^{2+}$ solution; (F) Time courses of whole-cell inward currents at $-74 \mathrm{mV}$ of Orai1 in co-expression with STIM1 under standard STIM1/Orai1 solution conditions. Inward currents activated upon passive store-depletion via $100 \mu \mathrm{M}$ EGTA compared to 20 mM EGTA are shown; (G) Respective I/V traces corresponding to (F); (H) Time course of SK3 + Orai1 mediated $\mathrm{K}^{+}$currents recorded using standard STIM1/Orai1 solution conditions with either $100 \mu \mathrm{M}$ or $20 \mathrm{mM}$ EGTA in the pipette solution; (I) The I/V relationship corresponding to (H); (J) I/V relationship of SK3 + Orai1 mediated $\mathrm{K}^{+}$currents recorded using standard STIM1/Orai1 solution conditions and $100 \mu \mathrm{M}$ EGTA in the pipette solution before (black) and after (red) addition of SK channel blocker NS8593 $(30 \mu \mathrm{M})$ and subsequent application of $\mathrm{La}^{3+}(10 \mu \mathrm{M})$. (inset) The remaining current upon NS8593 (red) displaying inward rectifying behavior was blocked by La ${ }^{3+}$ (blue). (K) The block diagram shows the current densities before and after application of SK channel blocker NS8593 for SK3, SK3 + Orai1, and SK3 + Orai1 + STIM1 $n>5$ measured at $+30 \mathrm{mV}$. The Mann-Whitney test was used for statistical comparison considering differences statistically significant at $p<0.05$. The asterisk $\left.{ }^{*}\right)$ highlights the statistical significance $(p<0.05)$ before and after application of SK channel blocker NS8593 to currents of SK3, SK3 + Orai1, and expressing cells. 
The asterisks $\left({ }^{* *}\right)$, as also indicated by corresponding color (light orange), highlight the statistical significance $(p<0.05)$ between the currents recorded upon individual transfections of SK3, SK3 + Orai1, and SK3 + Orai1 + STIM1. All experiments in figure were performed in normal HEK 293 cells.

Furthermore, we determined whether the above-mentioned solution conditions: physiological SK3 solution conditions with [EGTA $]_{\text {intra, }}$, used to characterize SK3 channel activation, allow STIM1-Orai1 activation. Using physiological SK3 solution conditions with $100 \mu \mathrm{M}$ EGTA in the pipette solution led to weak STIM1-Orai1 activation, which enhanced upon the exchange of the extracellular $\left[\mathrm{Ca}^{2+}\right]$ from 2 to $10 \mathrm{mM}$ (physiological SK3 solution conditions with high $\left[\mathrm{Ca}^{2+}\right]_{\text {extra }}$ ) (Figure 1D,E). Consistent with these findings, STIM1-Orai1-Ca ${ }^{2+}$ current activation was five-fold weaker in the presence of $100 \mu \mathrm{M}$ EGTA (standard STIM1/Orai1 solution conditions with low [EGTA] intra) than with 20 mM EGTA in the pipette solution (standard STIM1/Orai1 solution conditions), both in the presence of $10 \mathrm{mM} \mathrm{Ca}^{2+}$ extracellularly (Figure $1 \mathrm{~F}, \mathrm{G}$ ).

Overall, we confirmed that SK3 channel currents activate increasingly with elevated intracellular $\mathrm{Ca}^{2+}$ concentrations, both via increasing buffered $\mathrm{Ca}^{2+}$ concentrations as well as decreasing EGTA concentrations in the pipette solution. It turned out that $100 \mu \mathrm{M}$ EGTA in the pipette solution and $2 \mathrm{mM} \mathrm{Ca}^{2+}$ in the extracellular solution are suitable to further investigate the SK3-Orai1 interplay, as they allowed robust SK3 channel activation, but weak STIM1/Orai1 activation. Thus, we used physiological SK3 solution conditions with [EGTA $_{\text {intra, }}$ in particular with $100 \mu \mathrm{M}$ EGTA intracellularly and $2 \mathrm{mM} \mathrm{Ca}^{2+}$ extracellularly in the following experiments to determine $\mathrm{SK} 3 \mathrm{~K}^{+}$currents and its potential interplay with Orai1.

\subsection{Orai1 Boosts SK3 Channel Activation}

In this part of the study, we investigated whether a potential interplay of SK3 and Orai1, as it occurs in specific cancer cell types [16,17], also applies to HEK 293 cells in the absence of STIM1.

Initially, we examined whether co-expression of Orai1 and SK3 in HEK 293 cells affects intracellular $\mathrm{Ca}^{2+}$ levels, as suggested for breast cancer cells $[16,17]$. Under physiological buffer conditions, we observed marginal, but not significant enhancement of basal $\mathrm{Ca}^{2+}$ levels with Fura-AM in SK3 and Orai1 co-expressing cells compared to only Orai1 or SK3 containing cells (Figure S3A). $\mathrm{Ca}^{2+}$ mediated NFAT activation was only slightly, but not significantly enhanced for SK3-Orai1 compared to only Orai1 or SK3 expressing cells (Figure S3B). From these experiments, we assume that there is only a minor rise in global cytosolic $\mathrm{Ca}^{2+}$ levels under physiological buffer conditions.

In the next step, we investigated whether Orai1 and SK3 co-expressing cells exhibit constitutive $\mathrm{Ca}^{2+}$ currents. Interestingly, using standard STIM1/Orai1 solution conditions with low [EGTA $]_{\text {intra }}$ buffering in electrophysiological experiments, SK3 and Orai1 coexpressing cells exhibited robust constitutive current activation (Figure $1 \mathrm{H}-\mathrm{K}$ ) with a double rectifying I/V relationship with a shape similar to SK3 $\mathrm{K}^{+}$currents obtained under physiological conditions. These currents were strongly reduced in the absence of Orai1 (Figures $1 \mathrm{~K}$ and S3C,E). Instead of using $100 \mu \mathrm{M}$ EGTA, $20 \mathrm{mM}$ EGTA in the pipette solution abolished these currents as well (standard STIM1/Orail solution conditions; Figure 1H,I). Application of NS8593, selectively interfering with SK1, SK2, and SK3 [65], significantly diminished currents developed in SK3 expressing cells in the presence of low [EGTA $]_{\text {intra }}$ (Figure 1J,K). For solely SK3 expressing cells, $\mathrm{K}^{+}$currents were fully inhibited upon NS8593 application (Figures 1K and S3C,E). Remarkably, for SK3-Orai1 expressing cells, a small, widely inward rectifying current with a reversal potential of $+40 \mathrm{mV}$ remained (Figures $1 \mathrm{~J}$ and $\mathrm{S} 3 \mathrm{D}, \mathrm{E})$. This remaining current was completely blocked via $10 \mu \mathrm{M} \mathrm{La}^{3+}$ (Figure 1J). The latter indicates that, contrary to SK3 expressing cells, Orai1SK3 co-expressing cells show not only $\mathrm{K}^{+}$permeation, but also $\mathrm{Ca}^{2+}$ influx, potentially via Orai1, in line with previous findings [16,17]. Moreover, our observations (Figure 1I-K) point to a potentiating effect of Orai1 on SK3 $\mathrm{K}^{+}$currents. 
Thus, in the following, we investigated, using defined symmetrical and physiological SK3 solution conditions with [EGTA $]_{\text {intra, }}$ whether SK3 $\mathrm{K}^{+}$currents are altered by the co-expression of Orai1. Indeed, SK3 $\mathrm{K}^{+}$currents were twice as high in the presence of Orai1 compared to its absence under both solution conditions (Figures 2A-C and S2D-F). It is noteworthy that in the absence of extracellular $\mathrm{Ca}^{2+}\left(0 \mathrm{mM} \mathrm{Ca}^{2+}\right)$ no SK3 $\mathrm{K}^{+}$currents are activated. Only upon the exchange to a $2 \mathrm{mM} \mathrm{Ca}^{2+}$ containing bath solution were SK3 $\mathrm{K}^{+}$ currents activated, which further increased in the presence of $10 \mathrm{mM} \mathrm{Ca}^{2+}$ (Figure 2D).

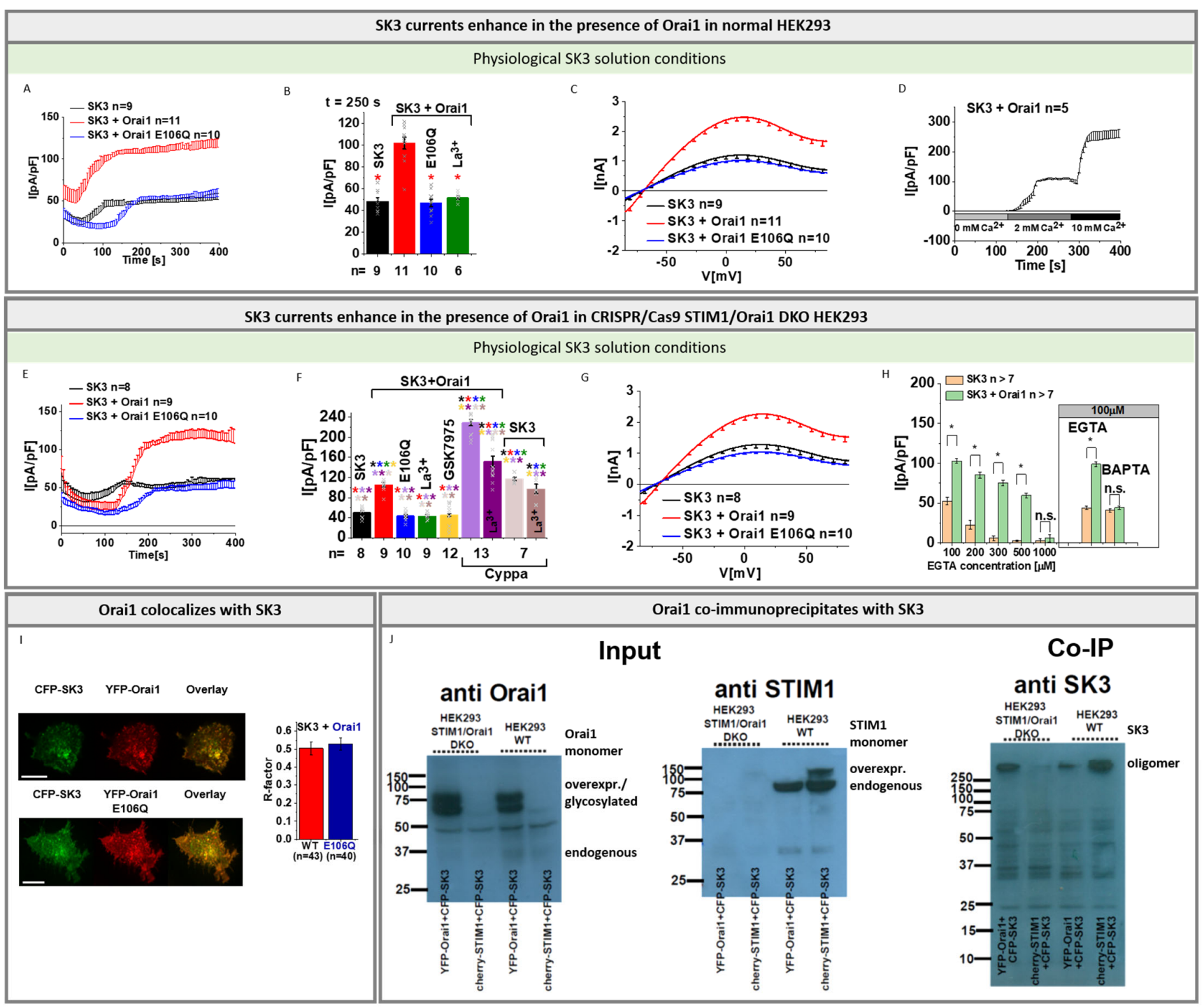

Figure 2. Orai1 enhances SK3 channel $\mathrm{K}^{+}$currents. (A) Time course of $\mathrm{K}^{+}$currents of SK3 expressing compared to SK3 and Orai1 or Orai1 E106Q co-expressing HEK 293 cells under physiological solution conditions. Pipette solution contains $100 \mu \mathrm{M}$ EGTA and $144 \mathrm{mM} \mathrm{K}^{+}$and bath solution contains $2 \mathrm{mM} \mathrm{Ca}^{2+}$ and $5 \mathrm{mM} \mathrm{K}^{+}$; (B) Block diagram with maximum current densities at $t=250 \mathrm{~s}$ corresponding to (A) and Orai1 + SK3 currents upon application of $10 \mu \mathrm{M} \mathrm{La}^{3+}$. The Mann-Whitney test was used for statistical comparison considering differences statistically significant at $p<0.05$. The asterisk $\left({ }^{*}\right)$, as also indicated by the corresponding color (red), highlights the statistical significance of the currents recorded upon individual transfections of SK3, SK3 + Orai1, SK3 + Orai1 E106Q, SK3 + Orai1 upon application of $10 \mu \mathrm{M} \mathrm{La}^{3+}$. The currents of SK3, SK3 + Orai1 E106Q and SK3 + Orai1 upon application of $10 \mu \mathrm{M} \mathrm{La}^{3+}$ are significantly reduced when compared to SK3 + Orai1; (C) The I/V relationship of maximum currents measured in (A); (D) Time course experiment of HEK 293 cells expressing SK3 + Orai1 upon application of $0 \mathrm{mM} \mathrm{Ca}^{2+}$ and subsequent switch to $2 \mathrm{mM} \mathrm{Ca}^{2+}$ followed by $10 \mathrm{mM} \mathrm{Ca}^{2+}$ solution; (E-G) Experiments identical to (A-C) performed in STIM1/Orai1 DKO HEK 293 cells, (F) includes in addition SK3 + Orai1currents upon application of $10 \mu \mathrm{M}$ GSK-7975A, $5 \mu \mathrm{M}$ Cyppa and $5 \mu \mathrm{M}$ Cyppa $+10 \mu \mathrm{M} \mathrm{La}^{3+}$ and SK3 currents upon application of $5 \mu \mathrm{M}$ Суppa and $5 \mu \mathrm{M}$ Cyppa $+10 \mu \mathrm{M} \mathrm{La}^{3+}$. The Mann-Whitney test was used for statistical comparison 
considering differences statistically significant at $p<0.05$. The asterisks $\left({ }^{*}\right)$, as also indicated by corresponding colors (black, red, blue, green, yellow, light purple, dark purple, light brown, dark brown), highlight the statistical significance of the currents recorded upon individual transfections of SK3, SK3 + Orai1, SK3 + Orai1 E106Q, SK3 + Orai1 upon application of $10 \mu \mathrm{M} \mathrm{La}^{3+}, 10 \mu \mathrm{M}$ GSK-7975A, $5 \mu \mathrm{M}$ Cyppa and $5 \mu \mathrm{M}$ Cyppa $+10 \mu \mathrm{M} \mathrm{La}^{3+}$ and SK3 currents upon application of $5 \mu \mathrm{M}$ Сурpa and $5 \mu \mathrm{M} \mathrm{Cyppa}+10 \mu \mathrm{M} \mathrm{La}^{3+}$. The asterisk of the particular color above the bar indicates the significance of $p<0.05$ to the corresponding individual bar of the same color, respectively, which is applicable for each bar; (H) Maximum $\mathrm{K}^{+}$currents of SK3 and SK3 + Orai1 expressing HEK 293 STIM1 DKO cells in response to different EGTA concentrations $(100,200,300,500$, and $1000 \mu \mathrm{M})$ or $100 \mu \mathrm{M}$ BAPTA in the pipette solution under physiological solution conditions. The Mann-Whitney test was used for statistical comparison considering differences statistically significant at $p<0.05$. The asterisks $\left(^{*}\right)$, as also indicated by corresponding color (black), highlights the statistical significance of the currents recorded upon different EGTA or BAPTA concentration upon overexpression of either SK3 or SK3 + Orai1; (I) Co-localization studies in STIM1/Orai1 DKO HEK 293 cells performed with a pixel-by-pixel analysis and the corresponding block diagram showing the comparison of YFP-Orai1 with CFP-SK3 and YFP-Orai1 E106Q with CFP-SK3 (scale bar: $10 \mu \mathrm{m}$ ); (J) Western blots of wild-type and STIM1/Orai1 DKO HEK 293 cells upon overexpression of either SK3 and Orai1 or SK3 and STIM1 showing either the input of Orai1 detected with an anti-Orai1 antibody, input of STIM1 detected with an anti-STIM1 antibody, or co-immunoprecipitation of Orai1 and SK3 or STIM1 and SK3 detected with an anti-SK3 antibody. While experiments in (A-D) were performed in normal HEK 293 cells, those in (E-G) were performed in STIM1/Orai1 DKO HEK 293 cells. Western blots and Co-IP were performed in both normal and STIM1/Orai1 DKO HEK 293 cells as indicated.

To examine whether endogenous STIM1 and Orai1 are involved in the Orai1 mediated boost of SK3 $\mathrm{K}^{+}$currents, we performed the above-described experiments analogously in CRISPR/Cas9 STIM1/Orai1 double knockout (STIM1/Orai1-DKO) HEK 293 cells verified by sequence analysis and Western blot (Figure S4A,B). In accordance with our observations in normal HEK 293 cells, we discovered significantly enhanced SK $3 \mathrm{~K}^{+}$currents in the presence compared to the absence of Orai1 (Figure 2E-G). In addition to the loss of SK3 $\mathrm{K}^{+}$ currents in the absence of extracellular $\mathrm{Ca}^{2+}\left(0 \mathrm{mM} \mathrm{Ca}^{2+}\right)$, and the sequential enhancement in SK3 $\mathrm{K}^{+}$currents with increasing extracellular $\mathrm{Ca}^{2+}$ concentrations (Figure 2D), the use of a divalent free $\mathrm{Na}^{+}$containing solution, known to permeate Orai1 channels [45,66-69], did not generate SK3 $\mathrm{K}^{+}$current activation (Figure S3F-H).

In support of these findings, not only the application of the general $\mathrm{Ca}^{2+}$ ion channel blocker $\mathrm{La}^{3+}(10 \mu \mathrm{M})$, but also of the CRAC channel blocker GSK-7975A $(10 \mu \mathrm{M})$ to cells expressing SK3 and Orai1 led to a reduction in $\mathrm{K}^{+}$currents similar to those obtained in SK3 containing cells in the absence of Orai1 (Figures 2B,F and S2E). Moreover, SK3 $\mathrm{K}^{+}$currents enhanced by the SK channel agonist Cyppa [62] were significantly inhibited by $\mathrm{La}^{3+}$ only in the presence, but not in the absence of Orai1 (Figure 2F). Additionally, in contrast to Orai1, the dominant-negative Orai1 pore mutant, Orai1 E106Q, when co-expressed with SK3, did not further stimulate SK3 mediated $\mathrm{K}^{+}$currents (Figures 2A-C,E-G and S2D-F). This suggests that enhancements of $\mathrm{SK} 3 \mathrm{~K}^{+}$currents in the presence of Orai1 are likely mediated via local $\mathrm{Ca}^{2+}$ entry across Orai1.

The SK3 current enhancing role of Orai1 is also evident when the intracellular $\mathrm{Ca}^{2+}$ concentration is varied using different EGTA concentrations. In the absence of Orai1, SK3 $\mathrm{K}^{+}$currents were readily observed in the presence of up to $100 \mu \mathrm{M}$ EGTA in the pipette and they significantly increased by the presence of Orai1. At higher (200-500 $\mu \mathrm{M})$ EGTA concentrations, however, activation of $\mathrm{K}^{+}$currents was only observed in the presence of Orai1. With $1 \mathrm{mM}$ EGTA in the pipette, no SK3-mediated $\mathrm{K}^{+}$currents were detectable, regardless of whether Orai1 was present or absent (Figures $2 \mathrm{H}$ and S2G). Moreover, when using $100 \mu \mathrm{M}$ BAPTA instead of $100 \mu \mathrm{M}$ EGTA, we discovered that SK3 $\mathrm{K}^{+}$currents were not further enhanced in the presence of Orai1 compared to its absence (Figures $2 \mathrm{H}$ and S3I).

It is worth mentioning that we verified overexpression of CFP-labelled SK3 and YFPOrai1 upon the individual or upon co-expression using confocal fluorescence microscopy (Figure S3J) as well as Western blot analysis in wild-type and STIM1/Orai1 DKO HEK 293 cells. (Figures 2J, S4C,D and S5A). Interestingly, single transfection of SK3 enabled only 
the detection of higher order oligomers (Figure S4C), while triple expression of SK3, Orai1, and STIM1 enabled the predominant detection of SK3 monomers (Figure S4D).

Moreover, we discovered clear co-localization of Orai1 and SK3 in specific spots of the cell membrane of HEK 293 cells, in line with previous reports showing their colocalization in breast cancer cells [16] (Figure 2I). Analysis of SK3 and Orai1 E106Q revealed a comparable level of co-localization (Figure 2I). Thus, reduced $\mathrm{K}^{+}$current densities of SK3 in the presence of Orai1-E106Q are most likely the result of abolished $\mathrm{Ca}^{2+}$ entry via the Orai1 pore mutant per se. In line with the co-localization of SK3 and Orai1, we discovered co-immunoprecipitation of SK3 and Orai1 in wild-type HEK 293 and HEK 293 STIM1/Orai1 DKO cells (Figures 2J and S5B), which is occurring to a much lower extent in STIM1/Orai1 DKO HEK 293 cells co-expressing SK3 and STIM1 (Figures 2J and S5B).

As we obtained in both normal and STIM1/Orai1 DKO HEK 293 cells comparable results, we performed our subsequent experiments in STIM1/Orai1 DKO HEK 293 cells only.

Moreover, we engineered an SK3 pore mutant, SK3 V544W, based on the cryo-EM structure of SK4 [53] (Figure S3K-sequence alignment). The substitution of valine to tryptophan at the narrowest part of the cytosolic gate [53] kept this mutant almost inactive. The expression of SK3 V544W and its co-localization with Orai1 remained comparable to that of SK3 (Figure S3K). Remarkably, while SK3 V544W showed significantly reduced currents compared to SK3 wild-type, Orai1, but not Orai1 E106Q, partially restored its activity (Figure S3L).

In summary, we clearly showed that Orai1- and SK3- co-expressing cells exhibit constitutive $\mathrm{K}^{+}$currents. Inhibition of SK3 $\mathrm{K}^{+}$currents left a tiny, mainly inward rectifying current with a $\mathrm{V}_{\text {rev }}$ in the range of $+40 \mathrm{mV}$, which could be blocked by $\mathrm{La}^{3+}$. This suggests that SK3 and Orai1 co-expressing cells develop marginal, local increases in intracellular $\mathrm{Ca}^{2+}$ levels, which is sufficient to boost SK3 $\mathrm{K}^{+}$currents. Orai1-induced SK3 $\mathrm{K}^{+}$current activation in HEK 293 cells is accompanied by their close co-localization. Enhancements of SK3 $\mathrm{K}^{+}$currents are specifically driven by Orai1, as this is impaired by the expression of the prominent Orai1 E106Q pore mutant as well as by the application of a CRAC channel blocker. In addition, the activity of an SK3 pore mutant could be partially restored by Orai1, suggesting that the close co-localization of SK3 and Orai1 allows allosteric interference with the SK3 pore opening mechanism.

\subsection{Orai1 Overrules the Inhibitory Effect of CaM Mutants on SK3 Channels}

While we reported here that Orai1 boosts SK3 $\mathrm{K}^{+}$currents, it is believed that SK channels are generally activated via CaM. Extensive electrophysiological and pull-down studies on SK2 channels, investigation of the effect of disease-related CaM mutants on SK3 [70] and recent structural resolutions on the SK4-CaM complex revealed clear evidence that their activation is driven by $\mathrm{Ca}^{2+}$ bound $\mathrm{CaM}[50,51,53,54,64,71]$. Due to the similar $\mathrm{Ca}^{2+}$ dose-response relationship of all SK channels and their conserved structural CaM binding domains, they are all assumed to be activated by CaM [53,54,71]. In line with previous studies on SK channels $[50,51,53,54,70,71]$, we provide using physiological SK3 solution conditions with [EGTA $]_{\text {intra }}$ experimental evidence that SK3 channels are regulated in a CaM dependent manner analogously. While the co-expression of $\mathrm{CaM}_{\mathrm{WT}}$ with SK3 leads to significantly enhanced $\mathrm{K}^{+}$currents (Figure $\mathrm{S} 6 \mathrm{~A}-\mathrm{D}$ ), the presence of the $\mathrm{CaM}_{1,2,3,4}$ $\left(\mathrm{CaM}_{\mathrm{MUT}}\right)$ mutant, deficient in $\mathrm{Ca}^{2+}$ binding at all four EF-hands, abolished $\mathrm{SK} 3 \mathrm{~K}^{+}$currents almost completely (Figures 3A,B and S6A,B). 

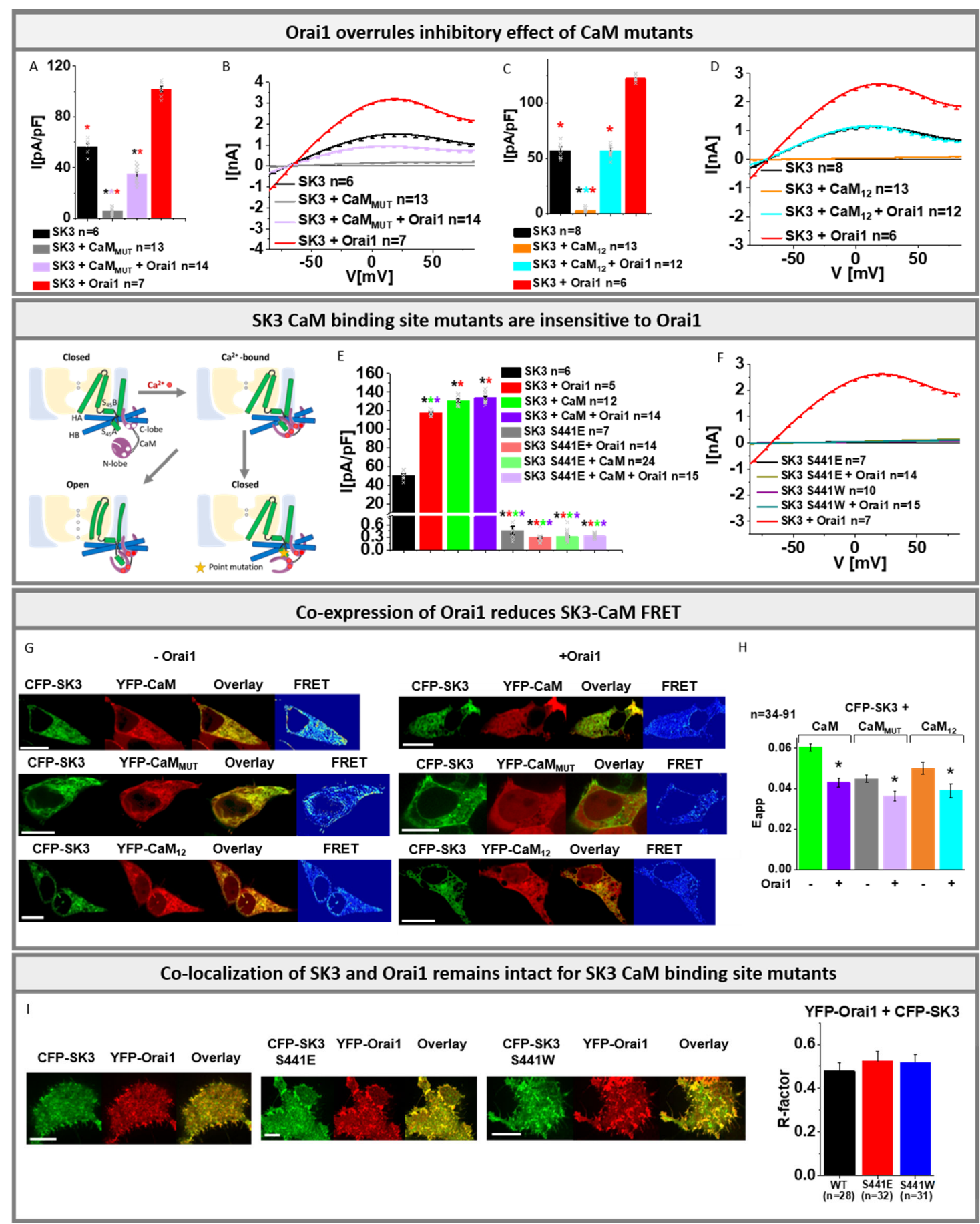

Figure 3. Orai1 overrules inhibitory effect of CaM mutants: (A) Block diagram with maximum current densities measured in STIM1/Orai1 DKO HEK 293 cells upon co-expression of CaM MUT with SK3 channel in the absence or presence of Orai1 in comparison to cells containing SK3 or SK3 + Orai1. The Mann-Whitney test was used for statistical comparison considering differences statistically significant at $p<0.05$. The asterisks $\left(^{*}\right)$, as also indicated by corresponding colors (black, red, light purple), highlight the statistical significance of the currents recorded upon individual transfections of SK3, SK3 + CaM $M U T$, $\mathrm{SK} 3+\mathrm{CaM}_{\mathrm{MUT}}+$ Orai1, SK3 + Orai1. The asterisk of the particular color above the bar indicates the significance of $p<0.05$ to the corresponding individual bar of the same color, respectively, which is applicable for each bar; (B) I/V relationship corresponding to (A); (C) Block diagram with maximum current densities measured in STIM1/Orai1 DKO HEK 293 cells upon co-expression of $\mathrm{CaM}_{12}$ with SK3 channel in the absence or presence of Orai1 in comparison to cells containing SK3 or 
SK3 + Orai1. The Mann-Whitney test was used for statistical comparison considering differences statistically significant at $p<0.05$. The asterisks $\left(^{*}\right)$, as also indicated by corresponding colors (black, red, cyan), highlight the statistical significance of the currents recorded upon individual transfections of SK3, SK3 $+\mathrm{CaM}_{12}, \mathrm{SK} 3+\mathrm{CaM}_{12}+$ Orai1, SK3 + Orai1. The asterisk of the particular color above the bar indicates the significance of $p<0.05$ to the corresponding individual bar of the same color, respectively, which is applicable for each bar; (D) I/V relationship corresponding to (C); Scheme represents the proposed structure of the single subunit of the SK channel with constitutively bound CaM. The subunit consists of 6 TM domains with the pore region located between the fifth and sixth segments. The opening mechanism of the channel is illustrated. Upon SK3 CaM point mutation the channel remains in the closed state; (E) Block diagram with maximum current densities measured upon expression of SK3 S441E, SK3 S441E + Orai1, SK3 S441E + CaM, and SK3 S441E + CaM + Orai1 compared to SK3, SK3 + Orai1, SK3 + CaM, and SK3 + CaM + Orai1 in STIM1/Orai1 DKO HEK 293 cells. The Mann-Whitney test was used for statistical comparison considering differences statistically significant at $p<0.05$ The asterisks $\left({ }^{*}\right)$, as also indicated by corresponding colors (black, red, green, purple), highlight the statistical significance of the currents recorded upon individual transfections of SK3 S441E, SK3 S441E + Orai1, SK3 S441E + CaM, and SK3 S441E + CaM + Orai1 compared to SK3, SK3 + Orai1, SK3 + CaM, and SK3 + CaM + Orai1. The asterisk of the particular color above the bar indicates the significance of $p<0.05$ to the corresponding individual bar of the same color, respectively, which is applicable for each bar; (F) I/V relationship of SK3 S441E, SK3 S441E + Orai1, SK3 S441W, and SK3 S441W + Orai1 compared to SK3 + Orai1; (G) Image series depict YFP-CaM with CFP-SK3 in STIM1/Orai1 DKO HEK 293 cells compared to YFP-CaM MUT $_{\text {Or }}$ YFP-CaM $_{12}$ with CFP-SK3, overlay and pixelwise calculated $\mathrm{N}_{\text {FRET }}$ index for a representative cell (scale bar: $10 \mu \mathrm{m}$ ) in the absence (left) and presence (right) of Orai1; (H) Bar graph diagram depicting FRET of heterologously overexpressed CaM and SK3 in comparison to $\mathrm{CaM}_{\mathrm{MUT}}$ or $\mathrm{CaM}_{12}$ and SK3 in the presence or absence of Orai1. The asterisk highlights the statistical significance $(p<0.05)$. (I) Co-localization studies in STIM1/Orai1 DKO HEK 293 cells performed with a pixel-by-pixel analysis and the corresponding block diagram showing the comparison of YFP-Orai1 with CFP-SK3, YFP-Orai1 with CFP-SK3 S441E, and YFP-Orai1 with CFP-SK3 S441W (scale bar: $10 \mu \mathrm{m}$ ). All experiments in figure were performed in STIM1/Orai1 DKO HEK 293 cells.

In the following, we investigated the effects of the $\mathrm{CaM}_{1,2}$ and $\mathrm{CaM}_{3,4}$ mutants deficient in $\mathrm{Ca}^{2+}$ binding to the $\mathrm{N}$ - and C-lobe, respectively. While $\mathrm{CaM}_{1,2}$ impaired SK3 mediated $\mathrm{K}^{+}$currents to a similar extent to CaM $\mathrm{MUT}_{\mathrm{T}}$ (Figure 3C,D), $\mathrm{CaM}_{3,4}$ led to similar enhancements in SK3 $\mathrm{K}^{+}$currents such as CaM $\mathrm{WT}_{\mathrm{T}}$ (Figure S6A,B). Moreover, we detected significant FRET and distinct co-localization for CFP- labeled SK3 and YFP-labeled CaM proteins and mutants confirming their direct interaction (Figures 3G,H and S6E). This suggests, in accordance with the previous reports on SK channels $[50,51,53,54,64,71]$, that CaM is constitutively bound to the SK3 channel and upon $\mathrm{Ca}^{2+}$ binding to its N-lobe it triggers conformational changes leading to pore opening.

We further investigated novel SK3 mutants assumed to be defective in CaM mediated activation, based on SK4 studies [53]. Indeed, SK3 S441E and SK3 S441W, containing the binding site for CaM N-lobe mutated, exhibited no activation upon co-expression with CaM or $\mathrm{CaM}_{3,4}$ (Figures 3E,F and S6H). Localization of these SK3 mutants and their FRET with CaM were maintained to a comparable extent as for SK3 wild-type (Figures 3I and S6I,J).

In the following, we continued to examine the effect of Orai1 on the interplay of SK3 and CaM. While co-expression of either CaM or Orai1 together with SK3 led to significantly increased $\mathrm{K}^{+}$currents, triple co-expression of SK3, CaM, and Orai1 further increased the currents only slightly. (Figures 3E and S6C,D,H). Thus, co-expression of Orai1 is sufficient to obtain almost maximum SK3 channel activity as obtained in the presence of CaM.

Interestingly, a co-expression of SK3, Orai1, and a CaM mutant $\left(\mathrm{CaM}_{\mathrm{MUT}}, \mathrm{CaM}_{1,2}\right)$ led to significantly enhanced $\mathrm{K}^{+}$currents compared to the abolished SK3 activity in the presence of a CaM mutant $\left(\mathrm{CaM}_{\mathrm{MUT}}, \mathrm{CaM}_{1,2}\right)$ without Orai1 (Figure 3A-D). The defective Orai1 E106Q was unable to overrule the inhibitory effect of the CaM $\mathrm{MUT}_{\mathrm{M}}$ on SK3 (Figure S6F,G). In line with these findings, a co-expression of SK3 CaM-binding-site mutants, SK3 S441E or SK3 S441W with Orai1 left the mutated channel inactive, both in the absence and presence of CaM (Figures 3E,F and S6H).

To determine whether Orai1 affects the SK3-CaM binding site, we investigated SK3CaM FRET in the absence compared to the presence of Orai1. Remarkably, the presence of 
Orai1 led to a significant reduction in FRET of CFP-SK3 with both YFP- CaM ${ }_{W T}$ as well as YFP-CaM mutants $\left(\mathrm{CaM}_{\mathrm{MUT}}, \mathrm{CaM}_{1,2}\right)$ (Figure $\left.3 \mathrm{G}, \mathrm{H}\right)$.

In accordance with these findings, the $\mathrm{K}^{+}$currents of the almost inactive SK3 V544W mutant were also partially recovered upon the co-expression of $\mathrm{CaM}$, which were not further enhanced by Orai1. Furthermore, while CaM MUT left the SK3 V544W mutant almost inactive, an additional co-expression of Orai1 also partially restored the activation of this SK3 pore mutant (Figure S3N).

In summary, we showed that $\mathrm{Ca}^{2+}$-mediated gating of SK3 channels is established via constitutively bound $\mathrm{CaM}$ which requires the N-lobe to be intact for $\mathrm{Ca}^{2+}$ binding. Abolished SK3 channel activity due to excess of the CaM MUT was restored in the presence of overexpressed Orai1, suggesting that Orai1 is able to compensate for disabled CaM function. The stimulatory action of Orai1 requires an intact CaM binding site within SK3. Restoration of SK3 currents in the presence of Orai1 in conjunction with reduced interaction of $\mathrm{CaM}_{\mathrm{WT}}$, as well as CaM mutants with SK3 in the presence of Orai1, suggests that Orai1 competes, either directly or allosterically, with CaM for the SK3 CaM binding site to boost $\mathrm{K}^{+}$currents.

\subsection{Both Orai1 N- and C-Termini Play a Crucial Role in the Interplay of Orai1 and SK3}

In the following, we investigated the molecular determinants within Orai1 required to maintain the interplay with SK3 using physiological SK3 solution conditions with [EGTA $]_{\text {intra. }}$.

Initially, we investigated two prominent loss-of-function Orai1 mutants, Orai1 K85E [37,72] and Orai1 L174D [73], known to interfere with the formation of a functional Orai1 pore [42], in the presence of the SK3 channel. Co-expression of either mutant with the SK3 channel revealed similar $\mathrm{K}^{+}$currents as seen for cells expressing SK3 alone, but they were significantly lower compared to those for SK3 in the presence of Orai1-WT (Figure 4A-D).

Confocal fluorescence microscopy exhibited comparable co-localization of SK3 with Orai1, Orai1 K85E, and Orai1 L174D (Figure 4E). In control experiments, we used two other Orai1 mutants (Orai1 L81K K85E and Orai1 E173K), that have been recently reported to restore or maintain an opening-permissive Orai1 conformation [42]. As expected Orai1 L81K K85E and Orai1 E173K retained the ability to enhance SK3 $\mathrm{K}^{+}$currents to a similar extent to Orai1-WT (Figure 4A-D). Thus, in accord with the Orai1 E106Q pore mutant, other mutations negatively affecting the Orai1 pore geometry interfere with the interplay with SK3.

Furthermore, we investigated whether Orai1 $\mathrm{N}$ - and/or C-terminal truncations affect the interplay with SK3. It is worth noting that the Orai1 $\mathrm{N}$ - and C-terminal deletion mutant, Orai1 79-281, cannot be activated via STIM1 upon store-depletion (Figure S7). Coexpression of Orai1 79-281 with SK3 led to an activation of $\mathrm{K}^{+}$currents to levels comparable to that of SK3 expressed alone, but they were significantly reduced compared to those obtained in the presence of Orai1-WT (Figure 4F,G). Deletion of the N-terminus only (Orai1 $\mathrm{N}_{1-78}$ ), which abolishes [37] STIM1 mediated Orai1 activation, also impaired the enhancement of SK3 mediated $\mathrm{K}^{+}$currents (Figure 4F,G,I). Co-localization of SK3 and Orai1 79-281 or Orai1 $\mathrm{N}_{1-78}$ reached comparable levels for SK3 and Orai1-WT (Figure $4 \mathrm{H}$ ). Interestingly, shorter N-terminal deletion mutants (Orai1 $\Delta \mathrm{N}_{1-38 / 47 / 64 / 71 / 72 / 74}$ ) (Figure 4I), that have been reported to retain STIM1-mediated Orai1 activation [37], were also fully or partially defective in boosting SK3 $\mathrm{K}^{+}$currents. Only Orai1 $\mathrm{N}_{1-26}$ was still able to increase SK3 $\mathrm{K}^{+}$currents (Figure $4 \mathrm{I}$ ). In line with the effects of the $\mathrm{N}$-terminal truncation mutant, we discovered that point mutants within the extended transmembrane Orai1 $\mathrm{N}$-terminal (ETON) region (aa 72-90), known to abolish STIM1-mediated activation, also interfere with the enhancement of SK3 $\mathrm{K}^{+}$currents (Figure 4J). Additionally, the C-terminus is required for an interplay with SK3, as the C-terminal deletion mutant Orai1 1-281, which shows significantly reduced STIM1-mediated Orai1 activation (Figure S7), exhibits a reduced SK3-Orai1 interplay. Interestingly, SK3-Orai1 1-281 co-localization remained unaffected (Figure $4 \mathrm{H}$ ). 


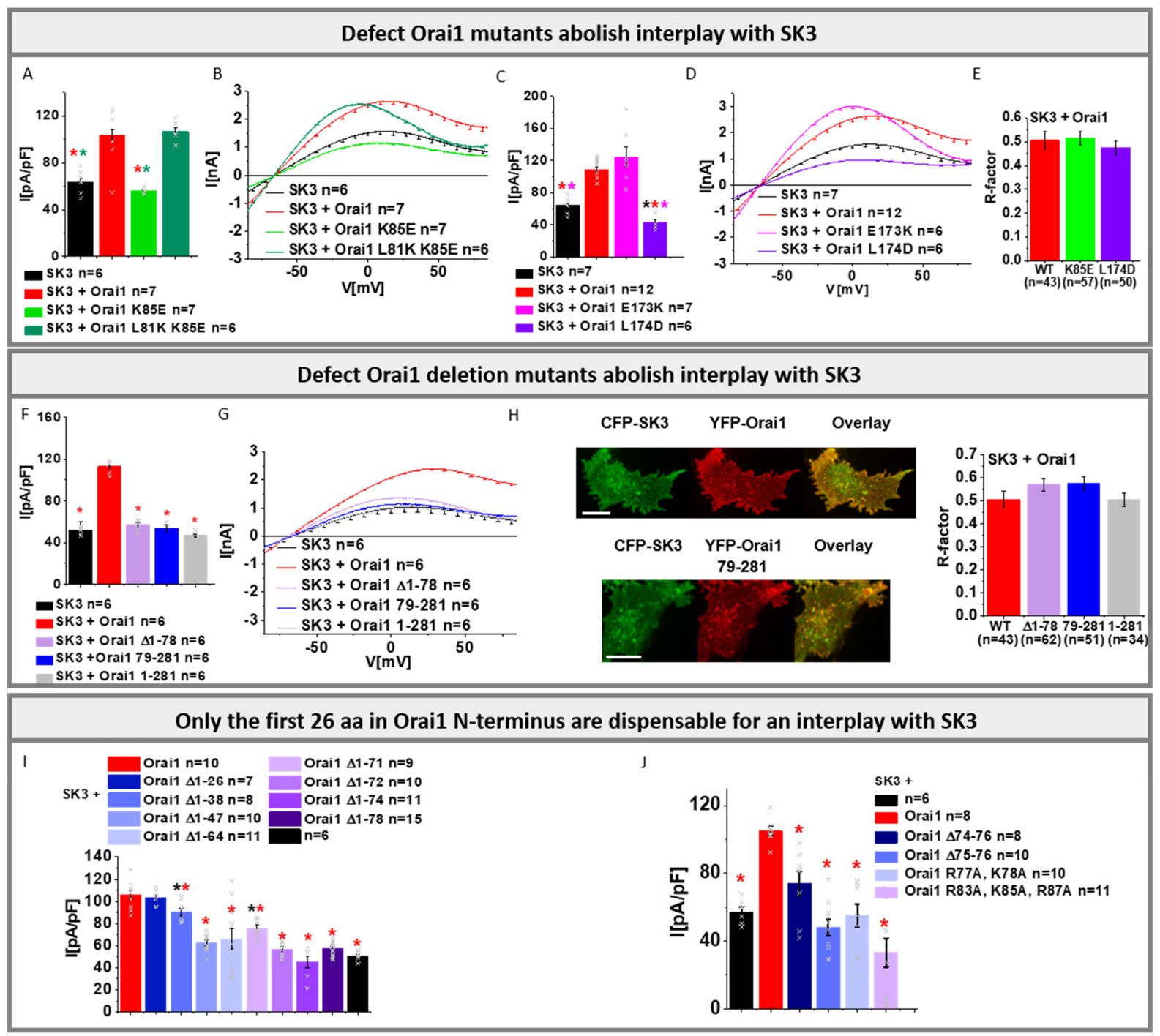

Figure 4. Critical sites within Orai1 that mediate co-regulation with SK3. (A) Block diagram with maximum current densities measured in CRISPR/Cas9 STIM1/Orai1 DKO HEK 293 cells upon co-expression of Orai1 K85E or Orai1 L81K K85E with SK3 channel in comparison to cells containing SK3 or SK3 + Orai1. The Mann-Whitney test was used for statistical comparison considering differences statistically significant at $p<0.05$. The asterisks $(*)$, as also indicated by corresponding colors (red, green), highlight the statistical significance of the currents recorded upon individual transfections of SK3, SK3 + Orai1, SK3 + Orai1 K85E and Orai1 L81K K85E. The asterisk of the particular color above the bar indicates the significance of $p<0.05$ to the corresponding individual bar of the same color, respectively, which is applicable for each bar; (B) I/V relationship corresponding to (A); (C) Block diagram with maximum current densities measured in STIM1/Orai1 DKO HEK 293 cells upon co-expression of Orai1 E173K or Orai1 L174D with SK3 channel in comparison to cells containing SK3 or SK3 + Orai1. The Mann-Whitney test was used for statistical comparison considering differences statistically significant at $p<0.05$. The asterisks $\left(^{*}\right)$, as also indicated by corresponding colors (black, red, pink), highlight the statistical significance of the currents recorded upon individual transfections of SK3, SK3 + Orai1, SK3 + Orai1 E173K and Orai1 L174D. The asterisk of the particular color above the bar indicates the significance of $p<0.05$ to the corresponding individual bar of the same color, respectively, which is applicable for each bar; (D) The I/V relationship corresponding to (C); (E) Co-localization block diagram performed in STIM1/Orai1 DKO HEK 293 cells with a pixel-by-pixel analysis showing the comparison of YFP-Orai1 K85E with CFP-SK3, and YFP-Orai1 L174D with CFP-SK3.; (F) Block diagram with maximum current densities measured in STIM1/Orai1 DKO HEK 293 cells upon co-expression of Orai1 $\Delta 1-78$, Orai1 79-281, or Orai1 1-281 with SK3 channel in comparison to cells containing SK3 or SK3 + Orai1. The Mann-Whitney test was used for statistical comparison considering differences statistically significant at $p<0.05$. The asterisks $\left(^{*}\right)$, as also indicated by 
corresponding colors (red), highlight the statistical significance of the currents recorded upon individual transfections of SK3, SK3 + Orai1, SK3 + Orai1 $\Delta 1-78$, SK3 + Orai1 79-281 and SK3 + Orai1 1-281. The asterisk of the particular color above the bar indicates the significance of $p<0.05$ to the corresponding individual bar of the same color, respectively, which is applicable for each bar; $(\mathbf{G})$ The I/V relationship corresponding to $(\mathbf{F}) ;(\mathbf{H})$ Co-localization studies performed in STIM1/Orai1 DKO HEK 293 cells with a pixel-by-pixel analysis showing the comparison of YFP-Orai1 79-281 with CFP-SK3 and YFP-Orai1 with CFP-SK3 and the corresponding block diagram showing additionally YFP-Orai1 $\Delta 1-78$ with CFP-SK3 (scale bar: $10 \mu \mathrm{m}$ ); (I) Block diagram with maximum current densities measured upon co-expression of SK3 with Orai1 $\Delta 1-26 / \Delta 1-38 / \Delta 1-47 / \Delta 1-64 / \Delta 1-71 / \Delta 1-72 / \Delta 1-74 / \Delta 1-78$ in comparison to SK3 and SK3 + Orai1. The Mann-Whitney test was used for statistical comparison considering differences statistically significant at $p<0.05$. The red asterisk represents the significance in relation to SK3 + Orai1, while the black asterisk shows the significance in relation to SK3; (J) Block diagram with maximum current densities measured upon co-expression of SK3 with Orai1 $\Delta 74-76$, Orai1 $\Delta 75-76$, Orai1 R77A K78A, and Orai1 R83A K85A R87A in comparison to SK3 and SK3 + Orai1. The Mann-Whitney test was used for statistical comparison considering differences statistically significant at $p<0.05$. The red asterisk represents the significance in relation to SK3 + Orai1. All experiments in figure were performed in STIM1/Orai1 DKO HEK 293 cells.

In conclusion, we discovered that Orai1 mediated SK3 $\mathrm{K}^{+}$current enhancements require an intact Orai1 pore conformation in line with our findings with the Orai1 E106Q pore mutants. This also supports our previous findings that the SK3-Orai1 interplay is likely driven by $\mathrm{Ca}^{2+}$ entry via Orai1. Moreover, almost the entire Orai1 N-terminus, except for the first $26 \mathrm{~N}$-terminal residues, and the rear part of the C-terminus, are indispensable for the co-regulation with SK3.

\subsection{STIM1 Is Not Required for, but Can Influence the SK3-Orai1 Interplay Either Inhibitory or Stimulatory}

It is well known that the direct binding of STIM1 to Orai1 induces its activation $[45,46]$. In the following, we investigated whether STIM1 can influence the SK3-Orai1 interplay using physiological SK3 solution conditions with [EGTA $]_{\text {intra, }}$ unless otherwise stated. Expression of STIM1 when co-expressed with Orai1 and SK3 was confirmed with Western blot (Figures S4D and S5D).

Initially, we employed an Orai1 C-terminal point mutant, Orai1 L273D, disabled in coupling to STIM1 [35,74], co-expressed it with SK3 and STIM1 and investigated SK3 mediated $\mathrm{K}^{+}$currents. Both in the absence and presence of STIM1, the co-expression of SK3 with Orai1 L273D resulted in comparable $\mathrm{K}^{+}$current activation as with Orai1-WT (Figure 5A-D). This suggests that STIM1 is not required to enhance SK3 currents by Orai1, similar as reported for breast cancer cells [16].

Remarkably, co-expression of SK3, Orai1-WT, and STIM1 revealed significantly reduced current activation compared to SK3-Orai1 alone (Figure 1K, Figures 5C,D and S3D,E). Notably, inhibition via the SK channel blocker NS8593 left an inward-rectifying current resembling the CRAC channel current (Figures $1 \mathrm{~K}$ and S3D,E). Indeed, the latter could be blocked by $\mathrm{La}^{3+}$ (Figure S3D,E), suggesting that it arises from STIM1/Orai1 activity (Figure 5F). Moreover, we observed almost no co-localization between SK3 and STIM1 (Figure S8A). Interestingly, upon store-depletion via thapsigargin, co-localization of SK3 and Orai1 in the presence of STIM1 was significantly reduced by approximately 50\% (Figure 5E,F). In the absence of STIM1, SK3-Orai1 co-localization remained unaltered upon store-depletion (Figure 5F). Vice versa, in the presence of SK3, STIM1-Orai1 co-localization upon store-depletion was significantly reduced by only $\sim 17 \%$ (Figure $5 \mathrm{G}$ ). This suggests that, upon store-depletion, Orai1 favors to move into clusters with STIM1 and away from SK3. Due to the use of physiological solution conditions in our electrophysiological experiments presented in Figure 5A-D, we expect only local $\mathrm{Ca}^{2+}$ entry in STIM1/Orai1 clusters (Figure 1F,G). This, together with the fluorescence microscopy studies, might explain the reduced $\mathrm{K}^{+}$currents for Orai1/SK3 containing cells in the presence compared to the absence of STIM1. 

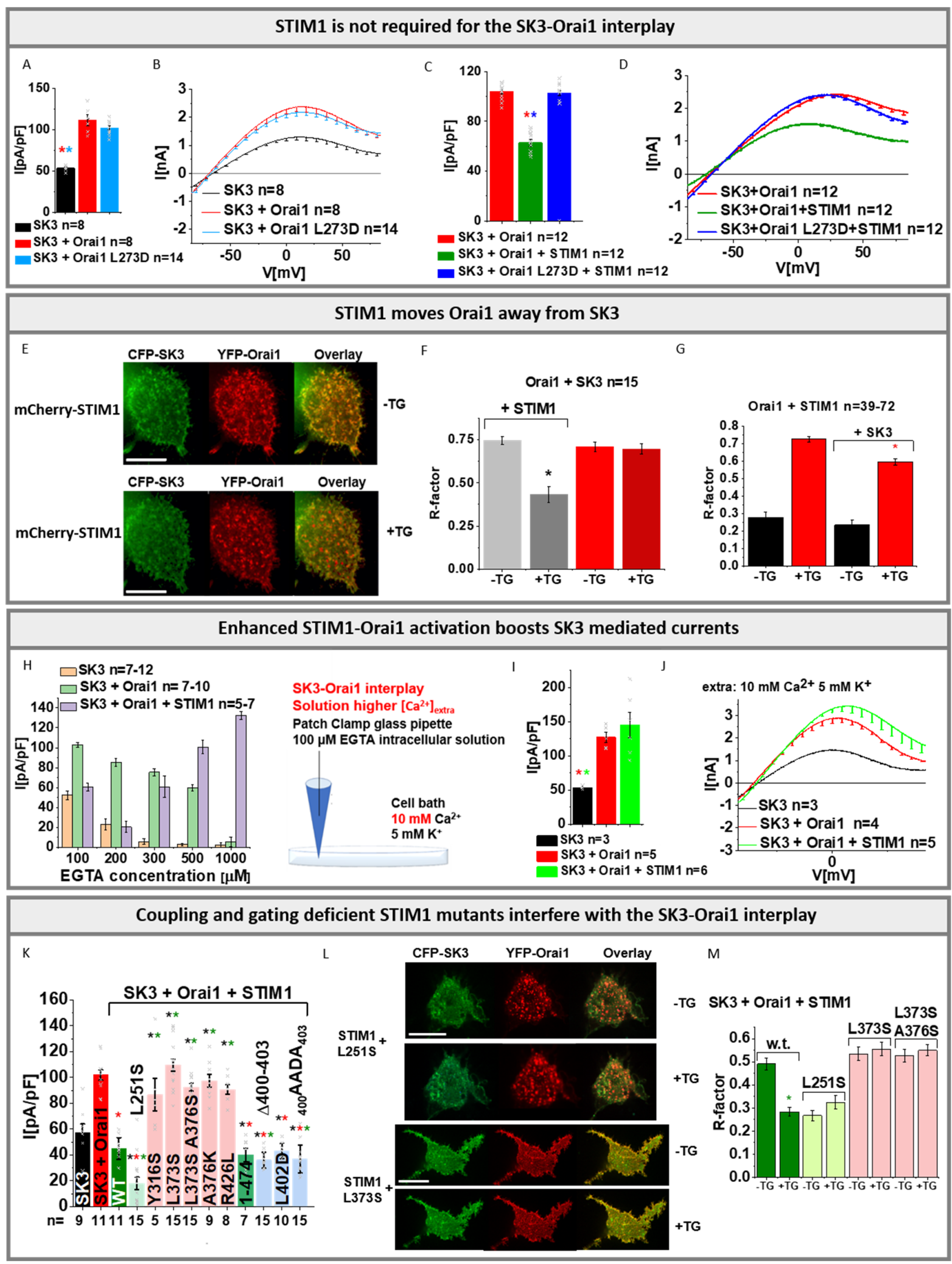

Figure 5. Functional coupling of STIM1 to Orai1 interferes with the SK3-Orai1 interplay. (A) Block diagram with maximum current densities measured in STIM1/Orai1 DKO HEK 293 cells upon co-expression of Orai1 L273D with SK3 channel in comparison to cells containing SK3 or SK3 + Orai1. The Mann-Whitney test was used for statistical comparison considering differences statistically significant at $p<0.05$. The asterisks $\left({ }^{*}\right)$, as also indicated by corresponding colors (red, light blue), highlight the statistical significance of the currents recorded upon individual transfections of SK3, SK3 + Orai1, SK3 + Orai1 L273D. The asterisk of the particular color above the bar indicates the significance of $p<0.05$ to the corresponding individual 
bar of the same color, respectively, which is applicable for each bar; (B) I/V relationship corresponding to (A); (C) Block diagram with maximum current densities measured in STIM1/Orai1 DKO HEK 293 cells upon co-expression of Orai1 L273D, SK3, and STIM1 in comparison to cells containing SK3 + Orai1 or SK3 + Orai1 + STIM1. The Mann-Whitney test was used for statistical comparison considering statistically significant differences at $p<0.05$. The asterisks $\left(^{*}\right)$, as also indicated by corresponding colors (red, blue), highlight the statistical significance of the currents recorded upon individual transfections of SK3, SK3 + Orai1 + STIM1, SK3 + Orai1 L273D + STIM1. The asterisk of the particular color above the bar indicates the significance of $p<0.05$ to the corresponding individual bar of the same color, respectively, which is applicable for each bar; (D) I/V relationship corresponding to (C); I Co-localization studies with a pixel-by-pixel analysis showing mCherry-STIM1, CFP-SK3, and YFP-Orai1 before and after application of thapsigargin; (F) The Pearson correlation coefficient (R-factor) gives a value for co-localizatiI(E) before and after thapsigargin treatment. An asterisk $\left(^{*}\right)$ indicates a significant difference in co-localization of SK3 and Orai1 before compared to after application of thapsigargin ( $t$-test: $p<0.05)$. The control experiment of SK3 + Orai1 in the absence of STIM1 does not reveal a significant difference before compared to after thapsigargin treatment; (G) The Pearson correlation coefficient (R-factor) gives a value for co-localization of Orai1 + STIM1 before and after thapsigargin treatment in the absence compared to the presence of SK3 channel. An asterisk $(*)$ indicates a significant difference in co-localization of STIM1 + Orai1 after application of thapsigargin ( $t$-test: $p<0.05)$ in the presence of SK3; $(\mathbf{H})$ Maximum $\mathrm{K}^{+}$currents of SK3, SK3 + Orai1, and SK3 + Orai1 + STIM1 expressing STIM1/Orai1 DKO HEK 293 cells in response to different EGTA concentrations in the pipette solution (100, 200, 300, 500, and $1000 \mu \mathrm{M}$ ) under physiological solution conditions; (I) Block diagram with maximum current densities measured in STIM1/Orai1 DKO HEK 293 cells upon co-expression of SK3 + Orai1 + STIM1 in comparison to cells containing SK3 or SK3 + Orai1 upon application of indicates the significance of $p<0.05$ to the corresponding individual bar of the same color, respectively, which is applicable for each bar; (J) I/V relationship corresponding to (I); (K) Block diagram with maximum current densities measured in STIM1/Orai1 DKO HEK 293 cells upon co-expression of SK3, Orai1, and STIM1 L251S/Y361S/L373/L373, A376S/A376K/R426L/1-474/ 4400-403/L402D/400AADA403 in comparison to cells containing SK3, SK3 + Orai1, or SK3 + Orai1 + STIM1. The Mann-Whitney test was used for statistical comparison considering differences statistically significant at $p<0.05$. The red asterisk represents the significance in relation to SK3 + Orai1, while the black asterisk shows the significance in relation to SK3 and the green asterisk indicates the significant difference to SK3 + Orai1 + STIM1; (L) Co-localization studies with a pixel-by-pixel analysis showing mCherry-STIM1 L251S or mCherry-STIM1 L373S, CFP-SK3, and YFP-Orai1 before and after application of thapsigargin; (M) The Pearson correlation coefficient (R-factor) gives a value for co-localization of (L) and additional STIM1 double mutant mCherry-STIM1 L373S co-expressed with CFP-SK3 and YFP-Orai1, all compared to mCherry-STIM1 WT, CFP-SK3, and YFP-Orai1 before and after thapsigargin treatment. An asterisk indicates a significant difference in co-localization of SK3 and Orai1 before compared to after application of thapsigargin ( $t$-test: $p<0.05)$. All experiments in figure were performed in STIM1/Orai1 DKO HEK 293 cells.

Nevertheless, the question arose whether global $\mathrm{Ca}^{2+}$ entry due to strong STIM1/Orai1 activation is also able to boost SK3 $\mathrm{K}^{+}$current activation. To investigate this aspect, we enhanced the EGTA concentration in the pipette solution (physiological SK3 solution conditions with [EGTA $\left.]_{\text {intra }}\right) ; 200 \mu \mathrm{M}$ EGTA in the pipette solution resulted in further reduced SK3 $\mathrm{K}^{+}$currents. Higher EGTA concentrations amounting to $300 \mu \mathrm{M}, 500 \mu \mathrm{M}$, and $1 \mathrm{mM}$ gradually increased SK3 $\mathrm{K}^{+}$currents (Figure $5 \mathrm{H}$ ). Remarkably, the enhanced storedepletion potentiates STIM1/Orai1 activation and increases SK3 $\mathrm{K}^{+}$currents. Moreover, while keeping $100 \mu \mathrm{M}$ EGTA in the pipette solution, but using a higher concentration of $10 \mathrm{mM} \mathrm{Ca}^{2+}$ instead of $2 \mathrm{mM} \mathrm{Ca}^{2+}$ in the extracellular solution, allowed SK3 $\mathrm{K}^{+}$current activation in STIM1/Orai1/SK3 co-expressing cells to similar levels as observed in cells expressing SK3 and Orai1 (Figure 5I,J), hence abolishing the inhibitory effect of STIM1. Overall, these findings substantiate that, under physiological conditions, STIM1 moves Orail away from SK3, and local enhancements in $\mathrm{Ca}^{2+}$ concentrations are not sufficient to boost SK3 channel activity. Enforcement of STIM1/Orai1 activation likely allows not only local, but also global $\mathrm{Ca}^{2+}$ elevations in the cell, enabling a to boost SK3 $\mathrm{K}^{+}$currents.

To further strengthen this concept, we employed, using $100 \mu \mathrm{M}$ EGTA in the pipette solution (physiological SK3 solution conditions with [EGTA] $]_{\text {intra }}$ ), several well-studied STIM1 mutants that are either constitutively opened (STIM1 L251S [34] and STIM1 1474 [75]) or locked in the closed conformation (STIM1 Y316S [76,77]; STIM1 L373S [78]; 
STIM1 L373S, A376S [78]; STIM1 A376K [34]; and STIM1 R426L [34]). We expected that constitutively active STIM1 mutants result in stronger inhibition, while the STIM1 inactive mutants show less or no STIM1-mediated inhibition of SK3 $\mathrm{K}^{+}$mediated currents in the presence of Orai1. Indeed, the constitutively open mutants, STIM1 L251S and STIM1 1-474 [67], showed significantly reduced SK3 $\mathrm{K}^{+}$current activation in the presence of Orai1 compared to those of SK3-Orai1 expressing cells. Co-expression of SK3 and Orai1 with each STIM1 mutant that is locked in the closed state revealed comparable current densities as detected for SK3-Orai1 in the absence of STIM1 (Figure 5K). In agreement with this, we already found reduced co-localization of SK3 and Orai1 in the presence of constitutively active STIM1 mutants before store-depletion, as shown, for example, for STIM1-L251S. Colocalization of SK3 and Orai1 remained unaltered for STIM1 mutants locked in the closed state, as exemplified by STIM1 L373S and STIM1 L373S A376S (Figure 5L,M). Additionally, we tested STIM1 mutants, that couple to Orai1, but impair Orai1 gating (STIM1 400-403, STIM1 L402D, and STIM1 ${ }_{400} \mathrm{AADA}_{403}$ ) [43]. Indeed, coupling of these STIM1 mutants was sufficient to significantly reduce Orai1-mediated SK3 $\mathrm{K}^{+}$currents (Figures $5 \mathrm{~K}$ and S8B). In accordance with the impairment of Orai1 gating of these STIM1 mutants, we showed that using $1 \mathrm{mM}$ EGTA in the pipette solution instead of $100 \mu \mathrm{M}$ led to almost completely abolished SK3 $\mathrm{K}^{+}$currents in the presence of Orai1 and STIM1 ${ }_{400} \mathrm{AADA}_{403}$, contrary to Orai1 and wild-type STIM1 (Figure S8C,D).

In summary, we show that Orai1-mediated SK3 current enhancements can occur independently of STIM1. Nevertheless, under physiological buffer conditions, STIM1 possesses an inhibitory role in SK3-Orai1 current activation, as it moves Orai1 away from SK3. Conversely, reinforcing STIM1-Orai1 activation and subsequent $\mathrm{Ca}^{2+}$ entry boosts SK3 $\mathrm{K}^{+}$currents.

\subsection{SK3 Channels Are Endogenously Expressed in LNCaP Cells}

Especially in breast, but also in colon cancer cells, the significance of the SK3-Orai1 interplay for proliferation and migration has already been extensively reported [16,18-20]. In prostate cancer, less is known about the potential relevance of the Orai1 and $\mathrm{K}^{+}$channel interplay. Here, we used the LNCaP (Lymph Node Carcinoma of the Prostate) cell line to examine whether SK3 plays a role in the proliferation of prostate cancer cells.

Initially, we investigated the $\mathrm{K}^{+}$current development in LNCaP cells using both, symmetrical and physiological SK3 solution conditions. Interestingly, we recorded I/V relationships typical of SK3 channel currents in particular in cells of passages (P) 3-5, but not earlier or later ones (Figure S9). It is worth noting that $\mathrm{K}^{+}$currents in P3-5 were significantly enhanced by overexpression of Orai1, as shown exemplarily for P4 (Figure S9). To analyze whether these currents are specific for endogenously expressed SK3, we applied diverse SK-sensitive agonists and antagonists. Initially, to confirm the SK3-specific action of diverse reported agonists and antagonists, we applied them to SK3 overexpressing HEK 293 cells. In line with Grunnet et al. [63], 1-EBIO $(50 \mu \mathrm{M})$, a general activator of SK channels, enhanced SK3 $\mathrm{K}^{+}$currents $\sim$ five-fold (Figure S10A,B). Furthermore, NS309, selective for SK1, SK3, and SK4, also drastically enhanced SK3 $\mathrm{K}^{+}$currents already at a $\mathrm{Ca}^{2+}$ concentration of $0.5 \mu \mathrm{M}$ (Figure S10C,D) in accordance with published studies [79]. Additionally, Cyppa, another selective activator of SK2 and SK3 [62], showed significant $\mathrm{K}^{+}$ current enhancements for HEK 293 cells heterologously expressing SK3 (Figure S10G,H). To specifically inhibit SK3 mediated $\mathrm{K}^{+}$currents, we applied NS8593, selectively interfering with SK1, SK2, and SK3 [65]. Indeed, we monitored significant inhibition of SK3 $\mathrm{K}^{+}$currents upon application of $10 \mu \mathrm{M}$ NS8593 (Figure S5E,F). 4-aminopyridine (4-AP), which has been reported to inhibit SK3, but SK2 channels $[63,80]$, exhibited significant inhibition of SK3 mediated $\mathrm{K}^{+}$currents at a concentration of $10 \mathrm{mM} 4$-AP (Figure $\mathrm{S} 10 \mathrm{H}, \mathrm{J}$ ).

Using these agonists and antagonists in electrophysiological studies, we then investigated SK3 $\mathrm{K}^{+}$current activation in LNCaP cells under both symmetrical and physiological solution conditions. Indeed, the application of both agonists, NS309 $(1 \mu \mathrm{M})$ and Cyppa $(5 \mu \mathrm{M})$ led to strongly pronounced $\mathrm{K}^{+}$currents, particularly in LNCaP cells of passages 
3-5. Obtained currents could be reversibly inhibited by the antagonist, NS8593 $(10 \mu \mathrm{M})$ (Figure S11D-G). Applying the principle of exclusion, one can find that these compounds likely activate and inhibit the activity of SK3 in LNCaP cells (Figure 6 inset). In support, weak expression of SK3 in LNCaP cells, in particular in passage 4, was detected with Western Blot (Figures S11A and S12). The band, in the range of $80-90 \mathrm{kDa}$, matches with the size of SK3 monomers of $81.4 \mathrm{kDa}$ and is in line with the detection of SK3 monomers in cells co-expressing SK3, Orai1, and STIM1 in HEK 293 cells. In agreement with our findings, the recent study by Bery et al. [81] discovered that SK3 is weakly expressed in LNCaP cells, which could be strongly upregulated by Enzalutamide treatment.
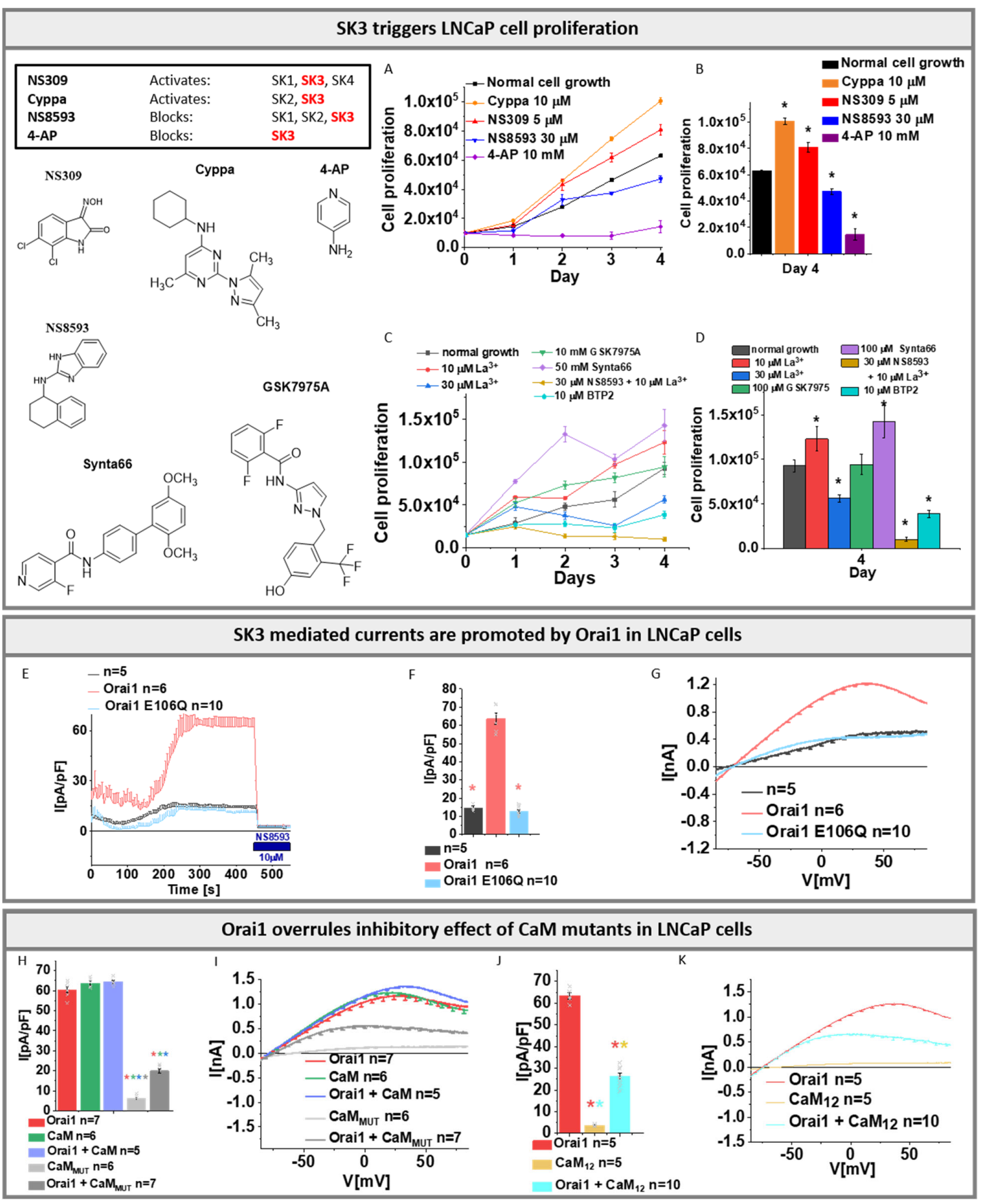

Figure 6. SK3-Orai1 interplay in LNCaP cells: Inset table and chemical structures represent the used agonist and antagonist of SK and Orai1 channels. (A) Cell viability of LNCaP cells after 24, 48, 72, and $96 \mathrm{~h}$ upon the treatment with SK3 channel agonist $10 \mu \mathrm{M}$ Cyppa, $5 \mu \mathrm{M}$ NS309, and antagonist $30 \mu \mathrm{M}$ NS8593, $10 \mathrm{mM}$ 4-AP detected via MTS assay; (B) Block diagram represents the cell proliferation of LNCaP cells after $96 \mathrm{~h}$ upon conditions described in (A). The Mann-Whitney test was 
used for statistical comparison considering differences statistically significantat $p<0.05$. The black asterisk represents the significance in relation to normal cell growth; (C) Cell viability of LNCaP cells after 24/48/72 and $96 \mathrm{~h}$ upon the treatment with Orai1 channel blocker $10 \mu \mathrm{M} \mathrm{La}^{3+}, 30 \mu \mathrm{M} \mathrm{La}^{3+}, 100 \mu \mathrm{M}$ GSK7975A, $100 \mu \mathrm{M}$ Synta66, the combination of Orai1 blocker $10 \mu \mathrm{M} \mathrm{La}^{3+}$ with SK3 channel antagonist $30 \mu \mathrm{M}$ NS8593 and $10 \mu \mathrm{M}$ BTP2 detected via MTS assay; (D) Block diagram represents the cell proliferation of LNCaP cells after $96 \mathrm{~h}$ upon conditions described in (C). The Mann-Whitney test was used for statistical comparison considering differences statistically significant at $p<0.05$. The black asterisk represents the significance in relation to normal cell growth; (E) Time course of LNCaP currents of endogenously expressed SK3 channel in the absence or presence of Orai1 or Orai1 E106Q. Pipette solution contains $100 \mu \mathrm{M}$ EGTA and $144 \mathrm{mM} \mathrm{K}^{+}$and bath solution contains $2 \mathrm{mM} \mathrm{Ca}^{2+}$ and $5 \mathrm{mM} \mathrm{K}^{+} ;(\mathbf{F})$ Block diagram with maximum current densities corresponding to (E). The Mann-Whitney test was used for statistical comparison considering differences statistically significant at $p<0.05$. The light red asterisk indicates the significance to Orai1; (G) I/V relationship of maximum currents measured in (E); (H) Block diagram with maximum current densities measured in LNCaP cells upon co-expression of CaM or CaM MUT with Orai1 in comparison to cells containing Orai1 or CaM MUT. The Mann-Whitney test was used for statistical comparison considering differences statistically significant at $p<0.05$. The asterisks $\left(^{*}\right)$, as also indicated by corresponding colors (red, green, purple, grey), highlight the statistical significance of the currents recorded upon individual transfections of Orai1, CaM, Orai1 $+\mathrm{CaM}, \mathrm{CaM}_{\text {MUT }}$ and Orai1 $+\mathrm{CaM}_{\text {MUT }}$. The asterisk of the particular color above the bar indicates the significance of $p<0.05$ to the corresponding individual bar of the same color, respectively, which is applicable for each bar; (I) The I/V relationship corresponding to $(\mathbf{H})$; $(\mathbf{J})$ Block diagram with maximum current densities measured in LNCaP cells upon co-expression of $\mathrm{CaM}_{12}$ with Orai1 in comparison to cells containing only Orai1 or $\mathrm{CaM}_{12}$. The Mann-Whitney test was used for statistical comparison considering differences statistically significant at $p<0.05$. The asterisks $\left({ }^{*}\right)$, as also indicated by corresponding colors (red, orange, cyan), highlight the statistical significance of the currents recorded upon individual transfections of Orai1, $\mathrm{CaM}_{12}$ and Orai1 $+\mathrm{CaM}_{12}$. The asterisk of the particular color above the bar indicates the significance of $p<0.05$ to the corresponding individual bar of the same color, respectively, which is applicable for each bar; (K) The I/V relationship corresponding to $(\mathrm{J})$. All experiments in figure were performed in LNCaP cells.

Next, we investigated whether there is a potential role of SK3 in proliferation. To determine the effect of the SK3 channel on LNCaP cell proliferation, we performed an MTS assay which allows us to monitor the behavior of cell growth in dependence of abovedescribed agonists (NS309 and Cyppa) and antagonists (NS8593 and 4-AP). The growth of the cells under those conditions was compared to the growth of untreated control cells after $24,48,72$, and $96 \mathrm{~h}$. The data revealed that $1 \mu \mathrm{M}$ NS309 led to a significantly enhanced cell proliferation compared to control cells, $96 \mathrm{~h}$ after the treatment (Figure S11B,C). Similarly, cells treated with $10 \mu \mathrm{M}$ Cyppa revealed significantly increased cell viability. The SK3 channel antagonist NS8593 $(30 \mu \mathrm{M})$ showed significantly reduced cell growth, compared to control cells. Among the antagonists, 4-AP is one of the most selective blockers of SK3 channels. While $3 \mathrm{mM}$ 4-AP already resulted in significant inhibition, $10 \mathrm{mM}$ almost completely inhibited the cell growth (Figures $6 \mathrm{~A}, \mathrm{~B}$ and $\mathrm{S} 11 \mathrm{~B}, \mathrm{C}$ ).

Additionally, STIM1 and Orai1 have been found to be expressed in LNCaP cells and to facilitate store-operated $\mathrm{Ca}^{2+}$ entry [82]. Investigation of the behavior of cell growth depending on Orai1 channel blockers revealed that only $30 \mu \mathrm{M} \mathrm{La}^{3+}$, but not $10 \mu \mathrm{M}$ $\mathrm{La}^{3+}$, reduced LNCaP cell proliferation. Notably, the use of $10 \mu \mathrm{M} \mathrm{La}^{3+}$ together with $30 \mu \mathrm{M}$ NS8593 further reduced the proliferation compared to the use of only the SK3 blocker NS8593. Intriguingly, among prominent CRAC channel blockers, only BTP2 $(10 \mu \mathrm{M})[83,84]$ significantly reduced proliferation, while GSK-7975A $(100 \mu \mathrm{M})[85,86]$ did not alter and Synta66 $(100 \mu \mathrm{M})$ [87] even significantly enhanced the proliferation of LNCaP cells (Figure 6C,D) as recently also reported for glioblastoma cells by Waldherr et al. [88] and metastatic renal cellular carcinoma by Dragoni et al. [89].

Altogether, these results reveal the presence of the SK3 channel in LNCaP cells, which plays a clear role in cell proliferation. Moreover, also $\mathrm{Ca}^{2+}$ entry into LNCaP cells is crucial for proliferation. However, whether this is specific to Orai1 remains unclear. To examine whether the SK3-Orai1 interplay persists also in LNCaP cells, we continued with electrophysiological experiments as described below. 


\subsection{SK3 Mediated Currents Are Promoted by Orai1 in LNCaP Cells}

To determine whether Orai1 also increases the $\mathrm{K}^{+}$currents in LNCaP cells, we overexpressed Orai1 or the Orai1 pore mutant E106Q and compared the obtained $\mathrm{K}^{+}$currents with those of non-transfected control cells. Orai1 overexpression revealed typical SK3 mediated $\mathrm{K}^{+}$currents using symmetrical as well as physiological solution conditions, with reversal potentials of $\sim 0 \mathrm{mV}$ and $-70 \mathrm{mV}$, respectively. Orai1 E106Q overexpression led to significantly reduced $\mathrm{K}^{+}$currents when compared to Orai1-WT expressing cells, similar to those of non-transfected control cells (Figures 6E-G and S11H-J). The application of $10 \mu \mathrm{M}$ NS8593 significantly blocked all recorded $\mathrm{K}^{+}$currents (Figures $6 \mathrm{E}$ and $\mathrm{S} 11 \mathrm{H}$ ). As a follow-up, we determined the SK3-mediated $\mathrm{K}^{+}$currents upon overexpression of CaM, $\mathrm{CaM}_{\mathrm{MUT}}$, or $\mathrm{CaM}_{1,2}$ in $\mathrm{LNCaP}$ cells, and the results were compared to those obtained in cells overexpressing Orai1-WT. Overexpression of CaM, with or without Orai1-WT, led to a comparable degree of $\mathrm{K}^{+}$current activation as with the overexpression of Orai1 alone (Figure 6H,I), in line with our observations in STIM1/Orai1-DKO HEK 293 cells (Figure 3). Both CaM mutants led to significantly reduced or almost completely abolished currents (Figure 6H-K). In line with our observations in STIM1/Orai1-DKO HEK 293 cells, those abolished currents could be rescued upon Orai1 co-expression. Our results indicate that LNCaP cells endogenously express SK3 channels and that Orai1 similarly promotes SK3-mediated $\mathrm{K}^{+}$currents as in HEK 293 cells. The SK3 $\mathrm{K}^{+}$currents already amplified with Orai1 are not further amplified by the coexpression of $\mathrm{CaM}$, which suggests that the effects of CaM and Orai1 are not additive. Indeed, CaM triggers SK3 channel activation, while $\mathrm{CaM}_{\mathrm{MUT}}$, in which $\mathrm{Ca}^{2+}$ binding is disabled, negatively affects the function of the channel. Interestingly, also in LNCaP cells, Orail compensates for inhibitory effects of the $\mathrm{CaM}_{\mathrm{MUT}}$ and enhances SK3 channel activation.

\section{Discussion}

Previous reports on breast and colon cancer cells [16,18-20,90-92] reported extensively that their proliferation is driven by a co-regulation of co-localized Orai1 and SK3 channels, while the molecular determinants for this remained unknown. In search of the latter, we discovered in this study that constitutive $\mathrm{Ca}^{2+}$ entry via Orai1 boosts SK3 mediated $\mathrm{K}^{+}$ currents, which is accompanied by their close colocalization. A crucial site in SK3 for the interplay with Orai1 represents the SK3-CaM binding domain. Within Orai1, an intact pore geometry, as well as intact $\mathrm{N}$ - and C-termini, are required to maintain the SK3-Orai1 co-regulation. This SK3-Orai1 interplay was not further promoted by STIM1. Instead, STIM1 can interfere with the co-localization of SK3-Orai1, moving, upon SOCE activation, Orai1 and SK3 apart from each other. In addition to the reported role of the SK3-Orai1 co-regulation in breast [17] and colon [19] cancer cells, we demonstrate using LNCaP cells that it also plays a role in prostate cancer cells.

In this study, we provide evidence that Orai1 and SK3 co-expressing cells exhibit constitutive currents upon low, but not high $\mathrm{Ca}^{2+}$ buffering via EGTA. Application of an SK3 channel inhibitor reduced those currents, while a small inward-rectifying current remained, which could be inhibited by $\mathrm{La}^{3+}$. This suggests that SK3-Orai1 expressing cells generate small, constitutive $\mathrm{Ca}^{2+}$ entry, in line with the previously reported enhanced $\mathrm{Ca}^{2+}$ levels in breast cancer cells compared to healthy breast cells, likely due to a unique interplay of SK3 and Orai1 in cancer cells [16].

Generally, SK3 $\mathrm{K}^{+}$currents develop with enhancing cytosolic $\mathrm{Ca}^{2+}$ concentrations. We demonstrated that SK3-Orai1 co-expressing cells show increased $\mathrm{K}^{+}$current activation compared to cells expressing SK3 only. Enhancements in SK3 $\mathrm{K}^{+}$currents in the presence of Orai1 likely arise from $\mathrm{Ca}^{2+}$ entry across Orai1. Indeed, using nominally $\mathrm{Ca}^{2+}$ -free or a divalent cation-free, $\mathrm{Na}^{+}$containing solution at the extracellular side abolished Orai1 mediated SK3 $\mathrm{K}^{+}$current enhancements. SK3 $\mathrm{K}^{+}$currents were gradually enhanced with increasing $\mathrm{Ca}^{2+}$ concentrations of the extracellular solution in the presence of Orai1. Moreover, different EGTA concentrations in the pipette solution always led to higher $\mathrm{K}^{+}$ current activation in cells containing SK3 and Orai1, compared to cells expressing SK3 only. 
Enhanced $\mathrm{Ca}^{2+}$ buffering via increasing EGTA concentrations from 200 to $500 \mu \mathrm{M}$ enabled activation of SK3 $\mathrm{K}^{+}$currents only in the presence of Orai1. Furthermore, $100 \mu \mathrm{M}$ BAPTA instead of $100 \mu \mathrm{M}$ EGTA in the pipette solution did not allow significant enhancements of SK3 $\mathrm{K}^{+}$currents in the presence compared to the absence of Orai1. Consistently, not only the application of $\mathrm{La}^{3+}$ blocks enhancement of Orai1 mediated SK3 $\mathrm{K}^{+}$currents, but also the application of the CRAC channel blocker GSK-7975A, as well as the co-expression of the prominent pore mutant Orai1 E106Q. Analogously, loss-of-function mutants, known to interfere with proper pore hydration and maintenance of an intact pore geometry (e.g., Orai1 K85E and Orai1 L174D) [37,42,93], impair Orai1 induced SK3 $\mathrm{K}^{+}$current enhancement. Therefore, the presence of Orai1 is a prerequisite for the pronounced $\mathrm{K}^{+}$current activation via SK3. High buffering of cytosolic $\mathrm{Ca}^{2+}$ or impaired Orai1 activity interferes with the positive feedback mechanism of the SK3-Orai1 interplay. Collectively, these results clearly indicate that SK3 channel activation is likely triggered via $\mathrm{Ca}^{2+}$ influx through Orai1 channels.

Within SK3, its CaM binding site emerged as crucial for the interplay with Orai1. Generally, SK channel currents enhance with increasing intracellular $\mathrm{Ca}^{2+}$ concentrations in a CaM dependent manner, as previously demonstrated $[50,51,53,54,64,70]$. Here, we further show that the $\mathrm{Ca}^{2+}$ dependent activation of SK3 is driven by constitutively bound $\mathrm{CaM}$, requiring two functional $\mathrm{Ca}^{2+}$ binding sites at the first and second $\mathrm{EF}$ hand. $\mathrm{CaM}$ mutants deficient in $\mathrm{Ca}^{2+}$ binding $\left(\mathrm{CaM}_{1,2}\right.$ or $\left.\mathrm{CaM}_{\mathrm{MUT}}\right)$ affect $\mathrm{SK} 3$ channel activity in an inhibitory manner. Orai1 did not further enhance $\mathrm{SK} 3 \mathrm{~K}^{+}$currents driven by overexpressed $\mathrm{CaM}$, demonstrating that the effects of Orai1 and CaM on SK3 are less likely additive. Remarkably, our data yield that the inhibitory effect of one of these CaM mutants can be partially overruled by Orai1. Interestingly, Orai1 reduces the interaction of both, $\mathrm{CaM}_{\mathrm{WT}}$ and CaM mutants with SK3, suggesting that Orai1 boosts SK3 channel activity, via either direct or indirect competition with the CaM binding site within the SK3 channel. In line with this, SK3 mutants which are defective in CaM binding cannot be activated by Orai1. The activation of an SK3 pore mutant could be partially restored by Orai1 or CaM, likely due to its still-intact CaM binding site. Overall, these results suggest that Orai1 enhances SK3 $\mathrm{K}^{+}$currents via an interplay with the SK3-CaM binding site, either directly or allosterically. Interestingly, diverse agonists, such as 1-EBIO [94-96], NS309 [79] and Cyppa [62], have also been reported to bind to the interaction interface of the CaM N-lobe and the SK channel $[97,98]$. In addition, PIP $_{2}$ has been shown to modulate SK2 channel activity via binding to the interface of CaM and the SK C-terminus [99].

Important regions within Orai1 that maintain the co-regulation with SK3 but are dispensable for their co-localization represent almost the entire $\mathrm{N}$ - and the C-termini, in addition to an intact pore region. Additionally, for the BKCa channel, it was recently shown that both cytosolic termini of Orai1 are important for their interplay [11]. In regard of the SK3-Orai1 interplay, only the first 26 amino acids in the Orai1 N-terminus are not required for the Orai1-mediated SK3 $\mathrm{K}^{+}$current enhancements. It is worth noting that the first part of the Orai1 N-terminus (aa 1-63) has been reported to include sites involved in cAMP-mediated phosphorylation and caveolin binding [100-105], and thus it might be involved in stabilizing the SK3-Orai1 interplay. Future investigations are required to determine the involvement of this region in the SK3-Orai1 interplay.

Furthermore, the enhancements of SK3 $\mathrm{K}^{+}$currents in the presence of Orail can occur independently of STIM1 in line with previous reports [16,20,52,57]. Accordingly, Orai1 boosts SK3 $\mathrm{K}^{+}$currents also in STIM1/Orai1-DKO HEK 293 cells. In addition, disturbed STIM1-Orai1 coupling sites in either STIM1 (e.g., STIM1 L373S) or Orai1 (Orai1 L273D) do not interfere with the enhancement of $\mathrm{K}^{+}$currents.

Nevertheless, STIM1 is able to affect the SK3-Orai1 interplay in an inhibitory manner under physiological ionic conditions. The reason for this is that, in STIM1/Orai1/SK3 co-expressing cells, Orai1 favors interplay with STIM1 upon store-depletion as revealed by patch-clamp and co-localization experiments. In support of this, our pool of critical STIM1 mutants in a quiescent or open conformation maintain or inhibit the SK3-Orai1 
co-regulation, respectively. It is possible that the expression level of STIM1, Orai1 and SK3 in different cell types determines whether either STIM1-Orai1 or SK3-Orai1 co-regulation becomes decisive.

Aside from physiological ionic conditions, enhanced EGTA concentrations in the pipette solution or increased $\mathrm{Ca}^{2+}$ concentrations outside the cell lead STIM1 to even stimulate $\mathrm{K}^{+}$currents in Orai1 and SK3 overexpressing cells. Herein, robust STIM1/Orai1 $\mathrm{Ca}^{2+}$ influx enhances SK3 mediated $\mathrm{K}^{+}$currents likely due to an increase in global $\mathrm{Ca}^{2+}$ levels within the cell. This is in line with the recent observation for $\mathrm{BKCa} \mathrm{K}^{+}$currents which could be further stimulated by STIM1-mediated Orai1 activation [11]. Under physiological solution conditions, STIM1 mediated Orai1 activation probably only allows local $\mathrm{Ca}^{2+}$ elevations. Due to the separation of STIM1-Orai1 complexes from SK3 channels, no $\mathrm{Ca}^{2+}$ influx mediated $\mathrm{K}^{+}$current activation can be established.

In addition, our data indicate that the SK3-Orai1 interplay also drives LNCaP cell proliferation. Our pharmacological findings, together with Western blot studies, suggest that SK3 is endogenously expressed in LNCaP cells in line with Bery et al. [81]. Furthermore, by using different SK channel drugs, we were able to narrow down that both SK3 and Orai1 are crucial for LNCaP cell proliferation. In line with our results in the standard overexpression system, we were also able to show in LNCaP cells that Orai1-WT promoted SK3 currents, while Orai1 E106Q failed to increase the current density. Additionally, CaM mutant-induced inhibition of SK3 $\mathrm{K}^{+}$currents was restored by Orai1. This further supports our hypothesis that an interplay of Orai1 and SK3 is crucial for LNCaP cell function and proliferation.

In future investigations, it yet must be determined whether and how accessory proteins establish the Orai1-SK3 interplay, stabilize the close co-localization of SK3 and Orai1, and/or assist STIM1 to move Orai1 away from SK3. There is considerable evidence that STIM1 and Orai1 activation is modulated via a series of other regulatory proteins [106-108]. Some prominent ones represent SigmaR1, SPCA2, and Caveolin [17,56,109]. SPCA2 has been reported to induce the constitutive activity of Orai1 independently of STIM1 in breast cancer cells [110]. In two separate studies, SigmaR1 has been demonstrated to interplay with STIM1 [111] and SK3 [56]. In breast and colon cancer cells, it has been shown that the SK3-Orai1 co-regulation occurs in cholesterol-rich regions $[16,19]$, indicating a potential role of cholesterol or Caveolin in determining the regulation of the SK3-Orai1 interplay [19,112-115].

\section{Conclusions}

Collectively, we discovered that close co-localization of SK3 and Orai1 enhances $\mathrm{K}^{+}$ current activation likely via local enhancements of $\mathrm{Ca}^{2+}$ levels across Orai1. Mechanistically, Orai1 competes with CaM, the typical SK channel activator, to increase SK3 activation via the CaM binding site. In addition, the SK3-Orai1 interplay requires both the Orai1-N- and the C-terminus but occurs independently of STIM1. Interestingly, STIM1 can disrupt their co-regulation by removing Orai1 from SK3. We demonstrate that the synergy of Orai1 and SK3 occurs not only in HEK 293 cells, but also exists in prostate cancer cells, where it likely regulates the function and growth.

Supplementary Materials: The following are available online at https: / www.mdpi.com/article / 10.3390 / cancers13246357/s1, Figure S1: Characterization of SK3 channel. Figure S2: SK3 currents under symmetrical solution conditions. Figure S3: Characterization of SK3 channel $\mathrm{K}^{+}$currents alone compared to the presence of Orai1 or STIM1/Orai1. Figure S4: Expression of SK3, Orai1, and STIM1. Figure S5: Original Western blots for HEK239 cells. Figure S6: SK3 channel currents are regulated via CaM. Figure S7: STIM1-mediated activation of Orai1 deletion mutants. Figure S8: SK3-Orai1 and STIM1. Figure S9: I/V relationships of $\mathrm{K}^{+}$currents in LNCaP cells. Figure S10: Effects of SK channel agonists and antagonists on SK3 channel currents. Figure S11: SK3 channel is endogenously expressed in LNCaP cells. Figure S12: Original Western blots of LNCaP cells. 
Author Contributions: A.T. and I.D. conceived the ideas, supervised the project, interpreted the data, and wrote the manuscript. A.T. prepared the original draft of the paper and performed electrophysiological experiments, biochemical work, cell proliferation, and analyzed the data. V.H. performed electrophysiological experiments and analyzed the data. R.S. (Romana Schober), M.S., H.G. and D.K. performed co-localization, life-scan, and FRET experiments. L.M. performed electrophysiological experiments. C.H., M.F., V.L. and I.F. cloned the constructs. R.B. and M.A.H. generated and experimentally confirmed DKO HEK 293 cell line. R.B., M.A.H. and R.S. (Rainer Schindl) contributed to the study design, revised the manuscript, and supported data analysis together with all other authors. All authors have read and agreed to the published version of the manuscript.

Funding: This research was funded in part by the Linz Institute of Technology project LIT-2018-05SEE-111 and the Austrian Science Fund (FWF) projects P30567, P32851 and to I.D., P32947 to M.F., P32075-B to I.F., P28701 and P32778 to R.S.and T-1190 to Ro.S. H.G. holds a PhD scholarship of the Austrian Science Fund (FWF) PhD program W1250 NanoCell. L.M. holds a PhD scholarship of Upper Austria within the FWF W1250-B20 Upper Austria DK NanoCell Project. DK is a member of the PhD program (DK) "Metabolic and Cardiovascular Disease" [FWF W1226]. Open Access Funding by the Austrian Science Fund (FWF).

Institutional Review Board Statement: Not applicable.

Informed Consent Statement: Not applicable.

Data Availability Statement: Reported Cancer databases can be found NCI's Genomic Data Commons (GDC). PanCanAtlas Publications: TCGA PanCancerAtlas; NCI's Genomic Data Commons: Bethesda, MD, USA. Available online: https: / / portal.gdc.cancer.gov/ (accessed on 14 December 2020).

Acknowledgments: We thank S. Buchegger for her excellent technical assistance.

Conflicts of Interest: The authors declare no conflict of interest.

\section{Appendix A}

Solution conditions used in the manuscript:

To study SK3 channel $\mathrm{K}^{+}$currents, we used symmetrical (intracellular and extracellular solutions contain $144 \mathrm{mM} \mathrm{KCl}$ ) and physiological (intracellular $144 \mathrm{mM} \mathrm{KCl}$, extracellular: $140 \mathrm{NaCl}, 5 \mathrm{KCl}$ ) solution conditions. To investigate the effects of intracellular $\mathrm{Ca}^{2+}$ levels on SK3 $\mathrm{K}^{+}$current activation, we used increasing buffered free $\mathrm{Ca}^{2+}$ concentration (symmetrical or physiological SK3 solution conditions with buffered $\left[\mathrm{Ca}^{2+}\right]_{\text {intra }}$ ) (increasing buffered $\mathrm{Ca}^{2+}$ concentration to $50,100,250,350,600,800$, and $1000 \mathrm{nM}$ were calculated according to the Single Chelator Metal Calculator, MaxChelator, $\mathrm{pH} 7.2$.) or varying EGTA concentration (symmetrical or physiological SK3 solution conditions with [EGTA] intra). To investigate the effect of extracellular $\mathrm{Ca}^{2+}$, we used $2 \mathrm{mM}$ or $10 \mathrm{mM} \mathrm{Ca}^{2+}$ in the respective SK3 extracellular solutions (e.g., physiological SK3 solution conditions with high $\left.\left[\mathrm{Ca}^{2+}\right]_{\text {extra }}\right)$. Subsequently, to SK3 $\mathrm{K}^{+}$current characterization, we used mainly the physiological SK3 solution conditions with [EGTA $]_{\text {intra }}$, containing $100 \mu \mathrm{M}$ EGTA intracellularly and $2 \mathrm{mM} \mathrm{Ca}^{2+}$ extracellularly, respectively, unless otherwise stated. In some experiments, we switched from physiological SK3 solution conditions to a $\mathrm{Na}^{+}$-DVF solution.

To determine STIM1-Orai1 $\mathrm{Ca}^{2+}$ current activation, we used typically standard STIM1/Orai1 solution conditions with $20 \mathrm{mM}$ EGTA intracellularly and $10 \mathrm{mM} \mathrm{Ca}^{2+}$, but no $\mathrm{K}^{+}$, neither intra- nor extracellularly. STIM1/Orai1 solution conditions with low [EGTA] $]_{\text {intra }}$ contained, instead of $20 \mathrm{mM}, 100 \mu \mathrm{M}$ EGTA intracellularly. STIM1/Orai1 solution conditions with low [EGTA $]_{\text {intra }} /$ low $\left[\mathrm{Ca}^{2+}\right]_{\text {extra }}$ contained intracellularly $100 \mu \mathrm{M}$ EGTA and extracellularly $2 \mathrm{mM} \mathrm{Ca}^{2+}$ (instead of $10 \mathrm{mM}$ ).

Detailed solution compositions are stated in Figure A1. 


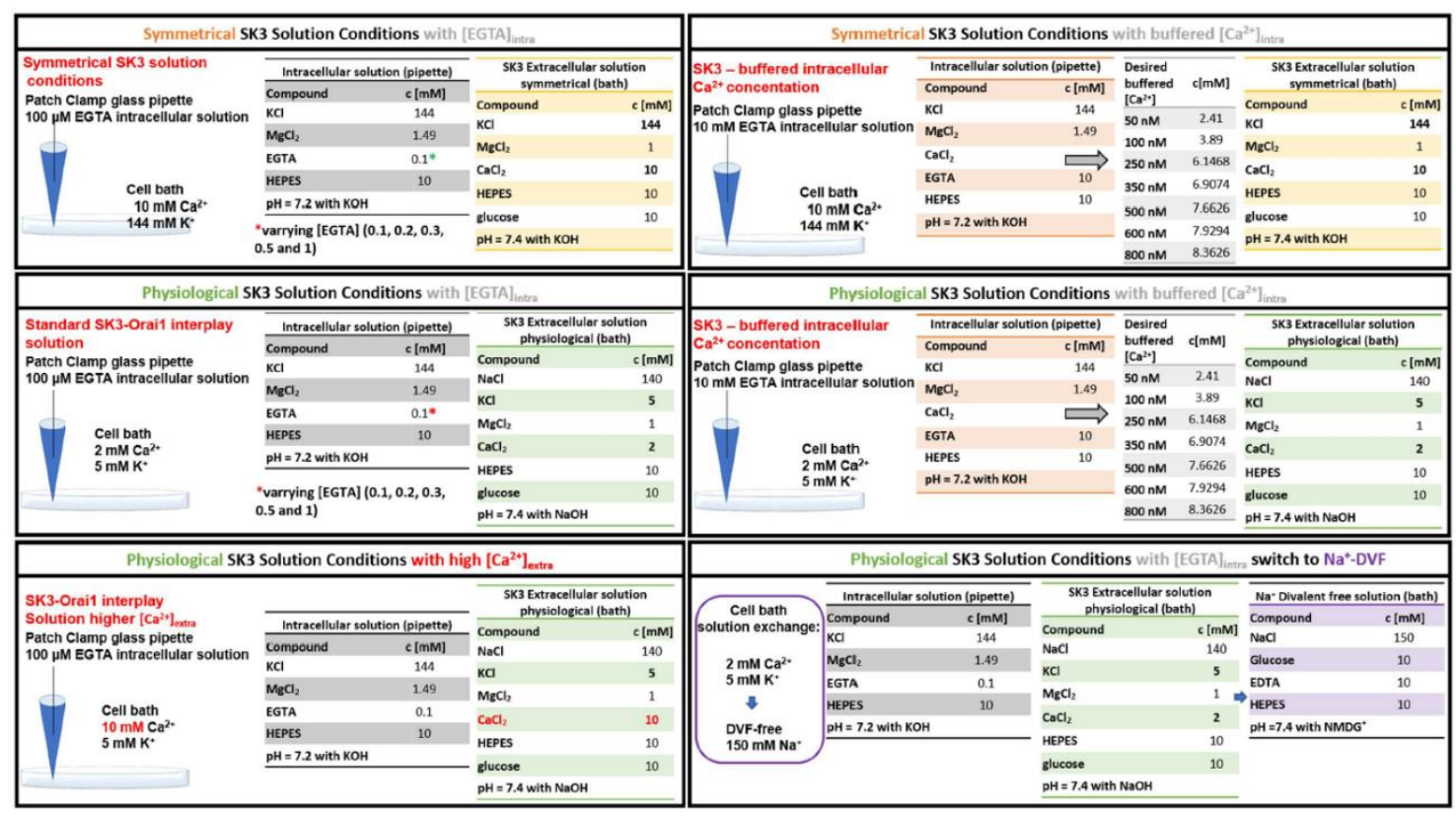

\begin{tabular}{|c|c|c|c|c|}
\hline \multicolumn{5}{|c|}{ Standard STIM1 Orai1 Solution Conditions } \\
\hline \multirow{3}{*}{$\begin{array}{l}\text { STIM1/Orai1 solutions } \\
\text { Patch Clamp glass pipette } \\
20 \text { mM EGTA intracellular solution }\end{array}$} & \multicolumn{2}{|c|}{ Intracellular solution (pipette) } & \multicolumn{2}{|c|}{ Extracellular solution (bath) } \\
\hline & Compound & c [mM] & Compound & $\mathrm{c}[\mathrm{mM}]$ \\
\hline & CsMethansulfonate & 145 & $\mathrm{NaCl}$ & 140 \\
\hline \multirow{5}{*}{$\begin{array}{l}\text { Cell bath } \\
10 \mathrm{mM} \mathrm{Ca}^{2+} \\
0 \mathrm{mM} \mathrm{K}^{+}\end{array}$} & $\mathrm{NaCl}$ & 8 & $\mathrm{CsCl}$ & 5 \\
\hline & $\mathrm{MgCl}_{2}$ & 5 & $\mathrm{MgCl}_{2}$ & 1 \\
\hline & HEPES & 10 & HEPES & 10 \\
\hline & EGTA & 20 & Glucose & 10 \\
\hline & \multicolumn{2}{|l|}{$\mathrm{pH}=7.2$ with $\mathrm{CsOH}$} & $\mathrm{CaCl}_{2}$ & 10 \\
\hline & & & \multicolumn{2}{|c|}{$\mathrm{pH}=7.4$ with $\mathrm{NaOH}$} \\
\hline
\end{tabular}

\begin{tabular}{|c|c|c|c|c|}
\hline \multicolumn{5}{|c|}{ STIM1 Orai1 Solution Conditions with low $[E G T A]_{\text {intra }}$} \\
\hline \multirow{4}{*}{$\begin{array}{l}\text { Low EGTA STIM1/Orai1 } \\
\text { solutions } \\
\text { Patch Clamp glass pipette } \\
100 \mu \text { MM EGTA intracellular solution }\end{array}$} & \multicolumn{2}{|c|}{ Intracellular solution (pipette) } & \multicolumn{2}{|c|}{ Extracellular solution (bath) } \\
\hline & Compound & $\mathrm{c}[\mathrm{mM}]$ & \multirow{2}{*}{$\begin{array}{l}\text { Compound } \\
\mathrm{NaCl}\end{array}$} & \multirow{2}{*}{$\mathrm{c}[\mathrm{mM}]$} \\
\hline & CsMethansulfonate & 145 & & \\
\hline & $\mathrm{NaCl}$ & 8 & $\mathrm{CsCl}$ & \multirow{2}{*}{$\begin{array}{l}5 \\
1\end{array}$} \\
\hline \multirow{4}{*}{$\begin{array}{l}\text { Cell bath } \\
10 \mathrm{mM} \mathrm{Ca}^{2+} \\
0 \mathrm{mM} \mathrm{K}^{+}\end{array}$} & $\mathrm{MgCl}_{2}$ & 5 & $\mathrm{MgCl}_{2}$ & \\
\hline & HEPES & 10 & HEPES & 10 \\
\hline & EGTA & 0.1 & \multirow{2}{*}{$\begin{array}{l}\text { Glucose } \\
\mathrm{CaCl}_{2}\end{array}$} & \multirow{2}{*}{$\begin{array}{l}10 \\
10\end{array}$} \\
\hline & \multicolumn{2}{|l|}{$\mathrm{pH}=7.2$ with $\mathrm{CsOH}$} & & \\
\hline 1 & & & \multicolumn{2}{|c|}{$\mathrm{pH}=7.4$ with $\mathrm{NaOH}$} \\
\hline
\end{tabular}

\begin{tabular}{|c|c|c|c|c|}
\hline \multicolumn{5}{|c|}{ STIM1 Orai1 Solution Conditions with low $[E G T A]_{\text {intra }} /$ low $\left[\mathrm{Ca}^{2+}\right]_{\text {extra }}$} \\
\hline \multirow{4}{*}{$\begin{array}{l}\text { Low EGTA STIM1/Orai1 } \\
\text { solutions } \\
\text { Patch Clamp glass pipette } \\
100 \mu \mathrm{M} \text { EGTA intracellular solution }\end{array}$} & \multicolumn{2}{|c|}{ Intracellular solution (pipette) } & \multicolumn{2}{|c|}{ Extracellular solution (bath) } \\
\hline & Compound & c ImMI & Compound & $c[\mathrm{mM}]$ \\
\hline & CsMethansulfonate & 145 & $\mathrm{NaCl}$ & 140 \\
\hline & $\mathrm{NaCl}$ & 8 & $\mathrm{CsCl}$ & 5 \\
\hline \multirow{5}{*}{$\begin{array}{l}\text { Cell bath } \\
2 \mathrm{mM} \mathrm{Ca}^{2+} \\
0 \mathrm{mM} \mathrm{K}^{+}\end{array}$} & $\mathrm{MgCl}_{2}$ & 5 & $\mathrm{MgCl}_{2}$ & 1 \\
\hline & HEPES & 10 & HEPES & 10 \\
\hline & EGTA & 0.1 & Glucose & 10 \\
\hline & $\mathrm{pH}=7.2$ with $\mathrm{CsOH}$ & & $\mathrm{CaCl}_{2}$ & 2 \\
\hline & & & \multicolumn{2}{|c|}{$\mathrm{pH}=7.4$ with $\mathrm{NaOH}$} \\
\hline
\end{tabular}

Figure A1. Solution conditions for SK3-Orai1 channel interplay. Throughout the investigations the solutions wer modified accordingly to the concentrations of different chemical compositions and named Symmetrical, Physiological and Standard SK3 solution conditions. For details please check the description in the Appendix A. 


\section{References}

1. Berridge, M.J.; Bootman, M.D.; Roderick, H.L. Calcium signalling: Dynamics, homeostasis and remodelling. Nat. Rev. Mol. Cell Biol. 2003, 4, 517-529. [CrossRef]

2. Berridge, M.J.; Lipp, P.; Bootman, M.D. The versatility and universality of calcium signalling. Nat. Rev. Mol. Cell Biol. 2000, 1, 11-21. [CrossRef] [PubMed]

3. Rosado, J.A.; Sage, S.O. The actin cytoskeleton in store-mediated calcium entry. J. Physiol. 2000, 526, 221-229. [CrossRef] [PubMed]

4. Jardin, I.; Diez-Bello, R.; Lopez, J.J.; Redondo, P.C.; Salido, G.M.; Smani, T.; Rosado, J.A. TRPC6 Channels Are Required for Proliferation, Migration and Invasion of Breast Cancer Cell Lines by Modulation of Orai1 and Orai3 Surface Exposure. Cancers 2018, 10, 331. [CrossRef] [PubMed]

5. Rosado, J.A. Calcium Entry Pathways in Non-excitable Cells. Preface. Adv. Exp. Med. Biol. 2016, 898, VII-VIII.

6. Capiod, T.; Haiech, J.; Heizmann, C.W.; Krebs, J.; Mignen, O. Calcium and Cell Fate. Biochim. Biophys. Acta (BBA) Bioenerg. 2016, 1863, 1335-1336. [CrossRef]

7. Debant, M.; Hemon, P.; Brigaudeau, C.; Renaudineau, Y.; Mignen, O. Calcium signaling and cell fate: How can Ca ${ }^{2+}$ signals contribute to wrong decisions for Chronic Lymphocytic Leukemic B lymphocyte outcome? Int. J. Dev. Biol. 2015, 59, 379-389. [CrossRef]

8. Prevarskaya, N.; Ouadid-Ahidouch, H.; Skryma, R.; Shuba, Y. Remodelling of $\mathrm{Ca}^{2+}$ transport in cancer: How it contributes to cancer hallmarks? Philos. Trans. R. Soc. B Biol. Sci. 2014, 369, 20130097. [CrossRef]

9. Gackière, F.; Warnier, M.; Katsogiannou, M.; Derouiche, S.; Delcourt, P.; Dewailly, E.; Slomianny, C.; Humez, S.; Prevarskaya, N.; Roudbaraki, M.; et al. Functional coupling between large-conductance potassium channels and Cav3.2 voltage-dependent calcium channels participates in prostate cancer cell growth. Biol. Open 2013, 2, 941-951. [CrossRef]

10. Hammadi, M.; Chopin, V.; Matifat, F.; Dhennin-Duthille, I.; Chasseraud, M.; Sevestre, H.; Ouadid-Ahidouch, H. Human ether à-gogo $\mathrm{K}^{+}$channel 1 (hEag1) regulates MDA-MB-231 breast cancer cell migration through Orai1-dependent calcium entry. J. Cell. Physiol. 2012, 227, 3837-3846. [CrossRef]

11. Wu, T.; Yin, N.; Chen, X.; Huang, H.; Liao, Y. Functional coupling between BKCa and SOC channels. Tissue Cell 2020, 66, 101394. [CrossRef] [PubMed]

12. Chen, M.; Li, J.; Jiang, F.; Fu, J.; Xia, X.; Du, J.; Hu, M.; Huang, J.; Shen, B. Orai1 forms a signal complex with BKC a channel in mesenteric artery smooth muscle cells. Physiol. Rep. 2016, 4, e12682. [CrossRef] [PubMed]

13. Duffy, S.M.; Ashmole, I.; Smallwood, D.T.; Leyland, M.L.; Bradding, P. Orai/CRACM1 and KCa3.1 ion channels interact in the human lung mast cell plasma membrane. Cell Commun. Signal. 2015, 13, 32. [CrossRef] [PubMed]

14. Lallet-Daher, H.; Roudbaraki, M.; Bavencoffe, A.; Mariot, P.; Gackière, F.; Bidaux, G.; Urbain, R.; Gosset, P.; Delcourt, P.; Fleurisse, L.; et al. Intermediate-conductance $\mathrm{Ca}^{2+}$-activated $\mathrm{K}^{+}$channels (IKCa1) regulate human prostate cancer cell proliferation through a close control of calcium entry. Oncogene 2009, 28, 1792-1806. [CrossRef]

15. Potier, M.-C.; Tran, T.A.; Chantome, A.; Girault, A.; Joulin, V.; Bougnoux, P.; Vandier, C.; Pierre, F. Altered SK3/KCa2.3-mediated migration in adenomatous polyposis coli (Apc) mutated mouse colon epithelial cells. Biochem. Biophys. Res. Commun. 2010, 397, 42-47. [CrossRef]

16. Chantôme, A.; Potier-Cartereau, M.; Clarysse, L.; Fromont, G.; Lambot, S.M.; Guéguinou, M.; Pages, J.-C.; Collin, C.; Oullier, T.; Girault, A.; et al. Pivotal Role of the Lipid Raft SK3-Orai1 Complex in Human Cancer Cell Migration and Bone Metastases. Cancer Res. 2013, 73, 4852-4861. [CrossRef]

17. Potier, M.; Joulin, V.; Roger, S.; Besson, P.; Jourdan, M.-L.; LeGuennec, J.-Y.; Bougnoux, P.; Vandier, C. Identification of SK3 channel as a new mediator of breast cancer cell migration. Mol. Cancer Ther. 2006, 5, 2946-2953. [CrossRef]

18. Song, K.; Zhong, X.-G.; Xia, X.-M.; Huang, J.-H.; Fan, Y.-F.; Yuan, R.-X.; Xue, N.-R.; Du, J.; Han, W.-X.; Xu, A.-M.; et al. Orai1 forms a signal complex with SK3 channel in gallbladder smooth muscle. Biochem. Biophys. Res. Commun. 2015, 466, 456-462. [CrossRef]

19. Guéguinou, M.; Harnois, T.; Crottes, D.; Uguen, A.; Deliot, N.; Gambade, A.; Chantôme, A.; Haelters, J.P.; Jaffrès, P.A.; Jourdan, M.L.; et al. SK3/TRPC1/Orai1 complex regulates SOCE-dependent colon cancer cell migration: A novel opportunity to modulate anti-EGFR mAb action by the alkyl-lipid Ohmline. Oncotarget 2016, 7, 36168-36184. [CrossRef]

20. Clarysse, L.; Guéguinou, M.; Potier-Cartereau, M.; Vandecasteele, G.; Bougnoux, P.; Chevalier, S.; Chantôme, A.; Vandier, C. cAMP-PKA inhibition of SK3 channel reduced both Ca2+ entry and cancer cell migration by regulation of SK3-Orai1 complex. Pflugers Arch. -Eur. J. Physiol. 2014, 466, 1921-1932. [CrossRef]

21. Tiffner, A.; Derler, I. Molecular Choreography and Structure of $\mathrm{Ca}^{2+}$ Release-Activated Ca ${ }^{2+}(\mathrm{CRAC})$ and $\mathrm{K}_{\mathrm{Ca} 2+} \mathrm{Channels}$ and Their Relevance in Disease with Special Focus on Cancer. Membranes 2020, 10, 425. [CrossRef]

22. Feske, S.; Gwack, Y.; Prakriya, M.; Srikanth, S.; Puppel, S.-H.; Tanasa, B.; Hogan, P.G.; Lewis, R.S.; Daly, M.; Rao, A. A mutation in Orai1 causes immune deficiency by abrogating CRAC channel function. Nature 2006, 441, 179-185. [CrossRef]

23. Prakriya, M.; Feske, S.; Gwack, Y.; Srikanth, S.; Rao, A.; Hogan, P.G. Orai1 is an essential pore subunit of the CRAC channel. Nature 2006, 443, 230-233. [CrossRef] [PubMed]

24. Liou, J.; Kim, M.L.; Do Heo, W.; Jones, J.T.; Myers, J.W.; Ferrell, J.E., Jr.; Meyer, T. STIM Is a Ca ${ }^{2+}$ Sensor Essential for Ca ${ }^{2+}-$ StoreDepletion-Triggered Ca ${ }^{2+}$ Influx. Curr. Biol. 2005, 15, 1235-1241. [CrossRef]

25. Zhang, S.L.; Yu, Y.; Roos, J.; Kozak, J.A.; Deerinck, T.J.; Ellisman, M.H.; Stauderman, K.A.; Cahalan, M.D. STIM1 is a Ca ${ }^{2+}$ sensor that activates CRAC channels and migrates from the $\mathrm{Ca}^{2+}$ store to the plasma membrane. Nature 2005, 437, 902-905. [CrossRef] [PubMed] 
26. Albarran, L.; Lopez, J.J.; Salido, G.M.; Rosado, J.A. Historical Overview of Store-Operated Ca ${ }^{2+}$ Entry. In Calcium Entry Pathways in Non-excitable Cells; Advances in Experimental Medicine and Biology; Rosado, J., Ed.; Springer: Cham, Switzerland, 2016; Volume 898, pp. 3-24. [CrossRef]

27. Parekh, A.B. Store-operated channels: Mechanisms and function. J. Physiol. 2008, 586, 3033. [CrossRef] [PubMed]

28. Calloway, N.; Vig, M.; Kinet, J.P.; Holowka, D.; Baird, B. Molecular clustering of STIM1 with Orai1/CRACM1 at the plasma membrane depends dynamically on depletion of $\mathrm{Ca}^{2+}$ stores and on electrostatic interactions. Mol. Biol. Cell 2009, 20, 389-399. [CrossRef]

29. Barr, V.A.; Bernot, K.M.; Srikanth, S.; Gwack, Y.; Balagopalan, L.; Regan, C.K.; Helman, D.J.; Sommers, C.L.; Oh-Hora, M.; Rao, A.; et al. Dynamic movement of the calcium sensor STIM1 and the calcium channel Orai1 in activated T-cells: Puncta and distal caps. Mol. Biol. Cell 2008, 19, 2802-2817. [CrossRef]

30. Park, C.Y.; Hoover, P.J.; Mullins, F.M.; Bachhawat, P.; Covington, E.D.; Raunser, S.; Walz, T.; Garcia, K.C.; Dolmetsch, R.E.; Lewis, R.S. STIM1 Clusters and Activates CRAC Channels via Direct Binding of a Cytosolic Domain to Orai1. Cell 2009, 136, 876-890. [CrossRef]

31. Schober, R.; Bonhenry, D.; Lunz, V.; Zhu, J.; Krizova, A.; Frischauf, I.; Fahrner, M.; Zhang, M.; Waldherr, L.; Schmidt, T.; et al. Sequential activation of STIM1 links $\mathrm{Ca}^{2+}$ with luminal domain unfolding. Sci. Signal. 2019, 12. [CrossRef]

32. Sallinger, M.; Tiffner, A.; Schmidt, T.; Bonhenry, D.; Waldherr, L.; Frischauf, I.; Lunz, V.; Derler, I.; Schober, R.; Schindl, R. Luminal STIM1 Mutants that Cause Tubular Aggregate Myopathy Promote Autophagic Processes. Int. J. Mol. Sci. 2020, 21, 4410. [CrossRef] [PubMed]

33. Baba, Y.; Hayashi, K.; Fujii, Y.; Mizushima, A.; Watarai, H.; Wakamori, M.; Numaga, T.; Mori, Y.; Iino, M.; Hikida, M.; et al. Coupling of STIM1 to store-operated $\mathrm{Ca}^{2+}$ entry through its constitutive and inducible movement in the endoplasmic reticulum. Proc. Natl. Acad. Sci. USA 2006, 103, 16704-16709. [CrossRef] [PubMed]

34. Muik, M.; Fahrner, M.; Schindl, R.; Stathopulos, P.; Frischauf, I.; Derler, I.; Plenk, P.; Lackner, B.; Groschner, K.; Ikura, M.; et al STIM1 couples to ORAI1 via an intramolecular transition into an extended conformation. EMBO J. 2011, 30, 1678-1689. [CrossRef]

35. Muik, M.; Frischauf, I.; Derler, I.; Fahrner, M.; Bergsmann, J.; Eder, P.; Schindl, R.; Hesch, C.; Polzinger, B.; Fritsch, R.; et al. Dynamic Coupling of the Putative Coiled-coil Domain of ORAI1 with STIM1 Mediates ORAI1 Channel Activation. J. Biol. Chem. 2008, 283, 8014-8022. [CrossRef]

36. Yuan, J.P.; Zeng, W.; Dorwart, M.R.; Choi, Y.-J.; Worley, P.F.; Muallem, S. SOAR and the polybasic STIM1 domains gate and regulate Orai channels. Nat. Cell Biol. 2009, 11, 337-343. [CrossRef]

37. Derler, I.; Plenk, P.; Fahrner, M.; Muik, M.; Jardin, I.; Schindl, R.; Gruber, H.J.; Groschner, K.; Romanin, C. The Extended Transmembrane Orai1 N-terminal (ETON) Region Combines Binding Interface and Gate for Orai1 Activation by STIM1*. J. Biol. Chem. 2013, 288, 29025-29034. [CrossRef]

38. McNally, B.A.; Somasundaram, A.; Jairaman, A.; Yamashita, M.; Prakriya, M. The C- and N-terminal STIM1 binding sites on Orai1 are required for both trapping and gating CRAC channels. J. Physiol. 2013, 591, 2833-2850. [CrossRef] [PubMed]

39. Tiffner, A.; Maltan, L.; Weiß, S.; Derler, I. The Orai Pore Opening Mechanism. Int. J. Mol. Sci. 2021, 22, 533. [CrossRef]

40. Tiffner, A.; Maltan, L.; Fahrner, M.; Sallinger, M.; Weiß, S.; Grabmayr, H.; Höglinger, C.; Derler, I. Transmembrane Domain 3 (TM3) Governs Orai1 and Orai3 Pore Opening in an Isoform-Specific Manner. Front. Cell Dev. Biol. 2021, 9. [CrossRef]

41. Butorac, C.; Krizova, A.; Derler, I. Review: Structure and Activation Mechanisms of CRAC Channels. In Calcium Signaling; Springer: Cham, Switzerland, 2019; Volume 1131, pp. 547-604. [CrossRef]

42. Tiffner, A.; Schober, R.; Höglinger, C.; Bonhenry, D.; Pandey, S.; Lunz, V.; Sallinger, M.; Frischauf, I.; Fahrner, M.; Lindinger, S.; et al. CRAC channel opening is determined by a series of Orail gating checkpoints in the transmembrane and cytosolic regions. J. Biol. Chem. 2021, 296, 100224. [CrossRef]

43. Butorac, C.; Muik, M.; Derler, I.; Stadlbauer, M.; Lunz, V.; Krizova, A.; Lindinger, S.; Schober, R.; Frischauf, I.; Bhardwaj, R.; et al. A novel STIM1-Orai1 gating interface essential for CRAC channel activation. Cell Calcium 2019, 79, 57-67. [CrossRef]

44. Fahrner, M.; Pandey, S.K.; Muik, M.; Traxler, L.; Butorac, C.; Stadlbauer, M.; Zayats, V.; Krizova, A.; Plenk, P.; Frischauf, I.; et al. Communication between $\mathrm{N}$ terminus and loop2 tunes Orai activation. J. Biol. Chem. 2018, 293, 1271-1285. [CrossRef]

45. Derler, I.; Butorac, C.; Krizova, A.; Stadlbauer, M.; Muik, M.; Fahrner, M.; Frischauf, I.; Romanin, C. Authentic CRAC channel activity requires STIM1 and the conserved portion of the Orai N terminus. J. Biol. Chem. 2018, 293, 1259-1270. [CrossRef]

46. Bergsmann, J.; Derler, I.; Muik, M.; Frischauf, I.; Fahrner, M.; Pollheimer, P.; Schwarzinger, C.; Gruber, H.J.; Groschner, K.; Romanin, C. Molecular Determinants within N Terminus of Orai3 Protein That Control Channel Activation and Gating. J. Biol. Chem. 2011, 286, 31565-31575. [CrossRef]

47. Li, Z.; Lu, J.; Xu, P.; Xie, X.; Chen, L.; Xu, T. Mapping the Interacting Domains of STIM1 and Orai1 in Ca ${ }^{2+}$ Release-activated Ca $^{2+}$ Channel Activation. J. Biol. Chem. 2007, 282, 29448-29456. [CrossRef]

48. Palty, R.; Stanley, C.; Isacoff, E.Y. Critical role for Orai1 C-terminal domain and TM4 in CRAC channel gating. Cell Res. 2015, 25, 963-980. [CrossRef] [PubMed]

49. Kar, P.; Lin, Y.-P.; Bhardwaj, R.; Tucker, C.J.; Bird, G.S.; Hediger, M.A.; Monico, C.; Amin, N.; Parekh, A.B. The N terminus of Orai1 couples to the AKAP79 signaling complex to drive NFAT1 activation by local $\mathrm{Ca}^{2+}$ entry. Proc. Natl. Acad. Sci. USA 2021, 118, e2012908118. [CrossRef] [PubMed]

50. Maylie, J.; Bond, C.T.; Herson, P.S.; Lee, W.-S.; Adelman, J.P. Small conductance $\mathrm{Ca}^{2+}$-activated $\mathrm{K}^{+}$channels and calmodulin. J. Physiol. 2004, 554, 255-261. [CrossRef] [PubMed] 
51. Lee, C.W.-S.; Ngo-Anh, T.J.; Bruening-Wright, A.; Maylie, J.; Adelman, J.P. Small Conductance Ca ${ }^{2+}$-activated $\mathrm{K}^{+} \mathrm{Channels}$ and Calmodulin. J. Biol. Chem. 2003, 278, 25940-25946. [CrossRef]

52. Guéguinou, M.; Chantôme, A.; Fromont, G.; Bougnoux, P.; Vandier, C.; Potier-Cartereau, M. KCa and Ca ${ }^{2+}$ channels: The complex thought. Biochim. Biophys. Acta (BBA) Bioenerg. 2014, 1843, 2322-2333. [CrossRef]

53. Lee, C.-H.; MacKinnon, R. Activation mechanism of a human SK-calmodulin channel complex elucidated by cryo-EM structures. Science 2018, 360, 508-513. [CrossRef]

54. Adelman, J.P. SK channels and calmodulin. Channels 2015, 10, 1-6. [CrossRef]

55. Ferreira, R.; Schlichter, L.C. Selective Activation of KCa3.1 and CRAC Channels by P2Y2 Receptors Promotes Ca ${ }^{2+}$ Signaling, Store Refilling and Migration of Rat Microglial Cells. PLoS ONE 2013, 8, e62345. [CrossRef] [PubMed]

56. Gueguinou, M.; Crottès, D.; Chantôme, A.; Rapetti-Mauss, R.; Potier-Cartereau, M.; Clarysse, L.; Girault, A.; Fourbon, Y.; Jézéquel, P.; Guérin-Charbonnel, C.; et al. The SigmaR1 chaperone drives breast and colorectal cancer cell migration by tuning SK3-dependent $\mathrm{Ca}^{2+}$ homeostasis. Oncogene 2017, 36, 3640-3647. [CrossRef] [PubMed]

57. Mignen, O.; Constantin, B.; Potier-Cartereau, M.; Penna, A.; Gautier, M.; Guéguinou, M.; Renaudineau, Y.; Shoji, K.F.; Félix, R.; Bayet, E.; et al. Constitutive calcium entry and cancer: Updated views and insights. Eur. Biophys. J. 2017, 46, 395-413. [CrossRef]

58. Girault, A.; Haelters, J.-P.; Potier-Cartereau, M.; Chantome, A.; Pinault, M.; Lambot, S.M.; Oullier, T.; Simon, G.; Couthon-Gourves, H.; Jaffres, P.-A.; et al. New Alkyl-Lipid Blockers of SK3 Channels Reduce Cancer Cell Migration and Occurrence of Metastasis. Curr. Cancer Drug Targets 2011, 11, 1111-1125. [CrossRef] [PubMed]

59. Klumpp, L.; Sezgin, E.C.; Skardelly, M.; Eckert, F.; Huber, S.M. KCa3.1 Channels and Glioblastoma: In Vitro Studies. Curr. Neuropharmacol. 2018, 16, 627-635. [CrossRef]

60. Parihar, A.S.; Coghlan, M.J.; Gopalakrishnan, M.; Shieh, C.-C. Effects of intermediate-conductance $\mathrm{Ca}^{2+}$-activated K ${ }^{+}$channel modulators on human prostate cancer cell proliferation. Eur. J. Pharmacol. 2003, 471, 157-164. [CrossRef]

61. Derler, I.; Hofbauer, M.; Kahr, H.; Fritsch, R.; Muik, M.; Kepplinger, K.; Hack, M.E.; Moritz, S.; Schindl, R.; Groschner, K.; et al. Dynamic but not constitutive association of calmodulin with rat TRPV6 channels enables fine tuning of $\mathrm{Ca}^{2+}$-dependent inactivation. J. Physiol. 2006, 577, 31-44. [CrossRef]

62. Hougaard, C.; Eriksen, B.L.; Jørgensen, S.; Johansen, T.H.; Dyhring, T.; Madsen, L.S.; Strøbaek, D.; Christophersen, P. Selective positive modulation of the SK3 and SK2 subtypes of small conductance $\mathrm{Ca}^{2+}$-activated $\mathrm{K}^{+}$channels. Br. J. Pharmacol. 2007, 151, 655-665. [CrossRef]

63. Grunnet, M.; Jespersen, T.; Angelo, K.; Frøkjær-Jensen, C.; Klaerke, D.A.; Olesen, S.-P.; Jensen, B.S. Pharmacological modulation of SK3 channels. Neuropharmacology 2001, 40, 879-887. [CrossRef]

64. Xia, X.-M.; Fakler, B.; Rivard, A.L.; Wayman, G.A.; Johnsonpais, T.L.; Keen, J.E.; Ishii, T.; Hirschberg, B.; Bond, C.T.; Lutsenko, S.V.; et al. Mechanism of calcium gating in small-conductance calcium-activated potassium channels. Nat. Cell Biol. 1998, 395, 503-507. [CrossRef] [PubMed]

65. Strøbæk, D.; Hougaard, C.; Johansen, T.H.; Sørensen, U.S.; Nielsen, E.; Nielsen, K.S.; Taylor, R.D.T.; Pedarzani, P.; Christophersen, P. Inhibitory Gating Modulation of Small Conductance $\mathrm{Ca}^{2+}$-Activated $\mathrm{K}^{+}$Channels by the Synthetic Compound (R)-N-(Benzimidazol-2-yl)-1,2,3,4-tetrahydro-1-naphtylamine (NS8593) Reduces Afterhyperpolarizing Current in Hippocampal CA1 Neurons. Mol. Pharmacol. 2006, 70, 1771-1782. [CrossRef]

66. Zhang, X.; Xin, P.; Yoast, R.E.; Emrich, S.M.; Johnson, M.T.; Pathak, T.; Benson, J.C.; Azimi, I.; Gill, D.L.; Monteith, G.R.; et al. Distinct pharmacological profiles of ORAI1, ORAI2, and ORAI3 channels. Cell Calcium 2020, 91, 102281. [CrossRef] [PubMed]

67. Krizova, A.; Maltan, L.; Derler, I. Critical parameters maintaining authentic CRAC channel hallmarks. Eur. Biophys. J. 2019, 48, 425-445. [CrossRef]

68. McNally, B.A.; Prakriya, M. Permeation, selectivity and gating in store-operated CRAC channels. J. Physiol. 2012, 590, 4179-4191. [CrossRef]

69. Prakriya, M.; Lewis, R.S. Regulation of CRAC Channel Activity by Recruitment of Silent Channels to a High Open-probability Gating Mode. J. Gen. Physiol. 2006, 128, 373-386. [CrossRef]

70. Saljic, A.; Muthukumarasamy, K.M.; La Cour, J.M.; Boddum, K.; Grunnet, M.; Berchtold, M.W.; Jespersen, T. Impact of arrhythmogenic calmodulin variants on small conductance $\mathrm{Ca}^{2+}$-activated $\mathrm{K}^{+}$(SK3) channels. Physiol. Rep. 2019, 7, e14210. [CrossRef]

71. Schumacher, M.A.; Rivard, A.F.; Bächinger, H.P.; Adelman, J.P. Structure of the gating domain of a Ca ${ }^{2+}$-activated K ${ }^{+}$channel complexed with $\mathrm{Ca}^{2+}$ /calmodulin. Nature 2001, 410, 1120-1124. [CrossRef]

72. Lis, A.; Zierler, S.; Peinelt, C.; Fleig, A.; Penner, R. A single lysine in the N-terminal region of store-operated channels is critical for STIM1-mediated gating. J. Gen. Physiol. 2010, 136, 673-686. [CrossRef] [PubMed]

73. Zhou, Y.; Cai, X.; Loktionova, N.A.; Wang, X.; Nwokonko, R.; Wang, X.; Wang, Y.; Rothberg, B.S.; Trebak, M.; Gill, D.L. The STIM1-binding site nexus remotely controls Orai1 channel gating. Nat. Commun. 2016, 7, 13725. [CrossRef] [PubMed]

74. Li, Z.; Liu, L.; Deng, Y.; Ji, W.; Du, W.; Xu, P.; Chen, L.; Xu, T. Graded activation of CRAC channel by binding of different numbers of STIM1 to Orai1 subunits. Cell Res. 2010, 21, 305-315. [CrossRef] [PubMed]

75. Derler, I.; Fahrner, M.; Muik, M.; Lackner, B.; Schindl, R.; Groschner, K.; Romanin, C. A Ca ${ }^{2+}$ Release-activated Ca ${ }^{2+}\left(C_{R A C}\right)$ Modulatory Domain (CMD) within STIM1 Mediates Fast $\mathrm{Ca}^{2+}$-dependent Inactivation of ORAI1 Channels. J. Biol. Chem. 2009, 284, 24933-24938. [CrossRef] [PubMed] 
76. Lopez, E.; Frischauf, I.; Jardin, I.; Derler, I.; Muik, M.; Cantonero, C.; Salido, G.M.; Smani, T.; Rosado, J.; Redondo, P.C. STIM1 phosphorylation at Y316 modulates its interaction with SARAF and the activation of SOCE and ICRAC. J. Cell Sci. 2019, 132, jcs.226019. [CrossRef]

77. Yu, J.; Zhang, H.; Zhang, M.; Deng, Y.; Wang, H.; Lu, J.; Xu, T.; Xu, P. An aromatic amino acid in the coiled-coil 1 domain plays a crucial role in the auto-inhibitory mechanism of STIM1. Biochem. J. 2013, 454, 401-409. [CrossRef] [PubMed]

78. Frischauf, I.; Muik, M.; Derler, I.; Bergsmann, J.; Fahrner, M.; Schindl, R.; Groschner, K.; Romanin, C. Molecular Determinants of the Coupling between STIM1 and Orai Channels: Differential Activation Of Orai1-3 Channels By A Stim1 Coiled-Coil Mutant. J. Biol. Chem. 2009, 284, 21696-21706. [CrossRef] [PubMed]

79. Strøbæk, D.; Teuber, L.; Jørgensen, T.D.; Ahring, P.K.; Kjær, K.; Hansen, R.S.; Olesen, S.P.; Christophersen, P.; Skaaning-Jensen, B. Activation of human IK and SK Ca ${ }^{2+}$-activated $\mathrm{K}^{+}$channels by NS309 (6,7-dichloro-1H-indole-2,3-dione 3-oxime). Biochim. Biophys. Acta (BBA) Biomembr. 2004, 1665, 1-5. [CrossRef]

80. Jäger, H.; Adelman, J.P.; Grissmer, S. SK2 encodes the apamin-sensitive $\mathrm{Ca}^{2+}$-activated $\mathrm{K}^{+}$channels in the human leukemic $\mathrm{T}$ cell line, Jurkat. FEBS Lett. 2000, 469, 196-202. [CrossRef]

81. Bery, F.; Cancel, M.; Guéguinou, M.; Potier-Cartereau, M.; Vandier, C.; Chantôme, A.; Guibon, R.; Bruyère, F.; Fromont, G.; Mahéo, K. Zeb1 and SK3 Channel Are Up-Regulated in Castration-Resistant Prostate Cancer and Promote Neuroendocrine Differentiation. Cancers 2021, 13, 2947. [CrossRef]

82. Vanoverberghe, K.; Lehen'Kyi, V.; Thebault, S.; Raphaël, M.; Abeele, F.V.; Slomianny, C.; Mariot, P.; Prevarskaya, N. Cytoskeleton Reorganization as an Alternative Mechanism of Store-Operated Calcium Entry Control in Neuroendocrine-Differentiated Cells. PLoS ONE 2012, 7, e45615. [CrossRef]

83. Zitt, C.; Strauss, B.; Schwarz, E.C.; Spaeth, N.; Rast, G.; Hatzelmann, A.; Hoth, M. Potent Inhibition of Ca ${ }^{2+}$ Release-activated $\mathrm{Ca}^{2+}$ Channels and T-lymphocyte Activation by the Pyrazole Derivative BTP2. J. Biol. Chem. 2004, 279, 12427-12437. [CrossRef]

84. Ishikawa, J.; Ohga, K.; Yoshino, T.; Takezawa, R.; Ichikawa, A.; Kubota, H.; Yamada, T. A pyrazole derivative, YM-58483, potently inhibits store-operated sustained $\mathrm{Ca}^{2+}$ influx and IL-2 production in T lymphocytes. J. Immunol. 2003, 170, 4441-4449. [CrossRef] [PubMed]

85. Derler, I.; Schindl, R.; Fritsch, R.; Heftberger, P.; Riedl, M.C.; Begg, M.; House, D.; Romanin, C. The action of selective CRAC channel blockers is affected by the Orai pore geometry. Cell Calcium 2013, 53, 139-151. [CrossRef]

86. Rice, L.V.; Bax, H.J.; Russell, L.J.; Barrett, V.J.; Walton, S.E.; Deakin, A.M.; Thomson, S.A.; Lucas, F.; Solari, R.; House, D.; et al. Characterization of selective Calcium-Release Activated Calcium channel blockers in mast cells and T-cells from human, rat, mouse and guinea-pig preparations. Eur. J. Pharmacol. 2013, 704, 49-57. [CrossRef]

87. van Kruchten, R.; Braun, A.; Feijge, M.A.H.; Kuijpers, M.J.E.; Rivera-Galdos, R.; Kraft, P.; Stoll, G.; Kleinschnitz, C.; Bevers, E.M.; Nieswandt, B.; et al. Antithrombotic Potential of Blockers of Store-Operated Calcium Channels in Platelets. Arter. Thromb. Vasc. Biol. 2012, 32, 1717-1723. [CrossRef] [PubMed]

88. Waldherr, L.; Tiffner, A.; Mishra, D.; Sallinger, M.; Schober, R.; Frischauf, I.; Schmidt, T.; Handl, V.; Sagmeister, P.; Köckinger, M.; et al. Blockage of Store-Operated $\mathrm{Ca}^{2+}$ Influx by Synta66 is Mediated by Direct Inhibition of the Ca ${ }^{2+}$ Selective Orai1 Pore. Cancers 2020, 12, 2876. [CrossRef] [PubMed]

89. Dragoni, S.; Turin, I.; Laforenza, U.; Potenza, D.M.; Bottino, C.; Glasnov, T.N.; Prestia, M.; Ferulli, F.; Saitta, A.; Mosca, A.; et al. Store-Operated $\mathrm{Ca}^{2+}$ Entry Does Not Control Proliferation in Primary Cultures of Human Metastatic Renal Cellular Carcinoma. BioMed Res. Int. 2014, 2014, 739494. [CrossRef]

90. Kouba, S.; Braire, J.; Félix, R.; Chantôme, A.; Jaffrès, P.-A.; Lebreton, J.; Dubreuil, D.; Pipelier, M.; Zhang, X.; Trebak, M.; et al. Lipidic synthetic alkaloids as SK3 channel modulators. Synthesis and biological evaluation of 2-substituted tetrahydropyridine derivatives with potential anti-metastatic activity. Eur. J. Med. Chem. 2019, 186, 111854. [CrossRef] [PubMed]

91. Cantonero, C.; Sanchez-Collado, J.; Gonzalez-Nuñez, M.; Salido, G.; Lopez, J.; Jardin, I.; Rosado, J. Store-independent Orai1mediated $\mathrm{Ca}^{2+}$ entry and cancer. Cell Calcium 2019, 80, 1-7. [CrossRef]

92. Herrera, F.E.; Sevrain, C.M.; Jaffrès, P.-A.; Couthon, H.; Grelard, A.; Dufourc, E.J.; Chantôme, A.; Potier-Cartereau, M.; Vandier, C.; Bouchet, A.M. Singular Interaction between an Antimetastatic Agent and the Lipid Bilayer: The Ohmline Case. ACS Omega 2017, 2, 6361-6370. [CrossRef]

93. Yamashita, M.; Ing, C.E.; Yeung, P.S.-W.; Maneshi, M.M.; Pomès, R.; Prakriya, M. The basic residues in the Orai1 channel inner pore promote opening of the outer hydrophobic gate. J. Gen. Physiol. 2019, 152, e201912397. [CrossRef] [PubMed]

94. Pedarzani, P.; Mosbacher, J.; Rivard, A.; Cingolani, L.A.; Oliver, D.; Stocker, M.; Adelman, J.P.; Fakler, B. Control of Electrical Activity in Central Neurons by Modulating the Gating of Small Conductance $\mathrm{Ca}^{2+}$-activated $\mathrm{K}^{+}$Channels. J. Biol. Chem. 2001, 276, 9762-9769. [CrossRef]

95. Jensen, B.S.; Strøbæk, D.; Christophersen, P.; Jørgensen, T.D.; Hansen, C.; Silahtaroglu, A.; Olesen, S.-P.; Ahring, P.K. Characterization of the cloned human intermediate-conductance $\mathrm{Ca}^{2+}$-activated $\mathrm{K}^{+}$channel. Am. J. Physiol. Physiol. 1998, 275, C848-C856. [CrossRef]

96. Devor, D.C.; Singh, A.K.; Frizzell, R.A.; Bridges, R.J. Modulation of Cl- secretion by benzimidazolones. I. Direct activation of a $\mathrm{Ca}^{2+}$-dependent $\mathrm{K}^{+}$channel. Am. J. Physiol. Cell. Mol. Physiol. 1996, 271, L775-L784. [CrossRef]

97. Zhang, M.; Pascal, J.M.; Schumann, M.; Armen, R.S.; Zhang, J.-F. Identification of the functional binding pocket for compounds targeting small-conductance $\mathrm{Ca}^{2+}$-activated potassium channels. Nat. Commun. 2012, 3, 1021. [CrossRef] 
98. Dong, H.; Zhang, Y.; Song, R.; Xu, J.; Yuan, Y.; Liu, J.; Li, J.; Zheng, S.; Liu, T.; Lu, B.; et al. Toward a Model for Activation of Orai Channel. iScience 2019, 16, 356-367. [CrossRef]

99. Zhang, M.; Meng, X.-Y.; Cui, M.; Pascal, J.M.; Logothetis, D.E.; Zhang, J.-F. Selective phosphorylation modulates the PIP2 sensitivity of the CaM-SK channel complex. Nat. Chem. Biol. 2014, 10, 753-759. [CrossRef]

100. Willoughby, D.; Everett, K.L.; Halls, M.L.; Pacheco, J.; Skroblin, P.; Vaca, L.; Klussmann, E.; Cooper, D.M.F. Direct Binding Between Orai1 and AC8 Mediates Dynamic Interplay Between $\mathrm{Ca}^{2+}$ and cAMP Signaling. Sci. Signal. 2012, 5, ra29. [CrossRef] [PubMed]

101. Calloway, N.; Owens, T.; Corwith, K.; Rodgers, W.; Holowka, D.; Baird, B. Stimulated association of STIM1 and Orai1 is regulated by the balance of PtdIns(4,5)P2 between distinct membrane pools. J. Cell Sci. 2011, 124, 2602-2610. [CrossRef]

102. Kawasaki, T.; Ueyama, T.; Lange, I.; Feske, S.; Saito, N. Protein Kinase C-induced Phosphorylation of Orai1 Regulates the Intracellular $\mathrm{Ca}^{2+}$ Level via the Store-operated Ca ${ }^{2+}$ Channel. J. Biol. Chem. 2010, 285, 25720-25730. [CrossRef] [PubMed]

103. Hooper, R.; Xuexin, Z.; Webster, M.; Go, C.; Kedra, J.; Marchbank, K.; Gill, D.L.; Weeraratna, A.T.; Trebak, M.; Soboloff, J. Novel Protein Kinase C-Mediated Control of Orai1 Function in Invasive Melanoma. Mol. Cell. Biol. 2015, 35, 2790-2798. [CrossRef]

104. Yu, F.; Sun, L.; Machaca, K. Constitutive recycling of the store-operated $\mathrm{Ca}^{2+}$ channel Orai1 and its internalization during meiosis. J. Cell Biol. 2010, 191, 523-535. [CrossRef] [PubMed]

105. Xuexin, Z.; Pathak, T.; Yoast, R.; Emrich, S.; Xin, P.; Nwokonko, R.M.; Johnson, M.; Wu, S.; Delierneux, C.; Gueguinou, M.; et al. A calcium/cAMP signaling loop at the ORAI1 mouth drives channel inactivation to shape NFAT induction. Nat. Commun. 2019, 10, 1971. [CrossRef]

106. Ambudkar, I.S. Cellular Domains That Contribute to $\mathrm{Ca}^{2+}$ Entry Events. Sci. STKE 2004, 2004, pe32. [CrossRef]

107. Gudlur, A.; Quintana, A.; Zhou, Y.; Hirve, N.; Mahapatra, S.; Hogan, P.G. STIM1 triggers a gating rearrangement at the extracellular mouth of the ORAI1 channel. Nat. Commun. 2014, 5, 5164. [CrossRef]

108. Lopez, J.J.; Albarran, L.; Gómez, L.J.; Smani, T.; Salido, G.M.; Rosado, J.A. Molecular modulators of store-operated calcium entry. Biochim. Biophys. Acta (BBA) Bioenerg. 2016, 1863, 2037-2043. [CrossRef]

109. Vashisht, A.; Trebak, M.; Motiani, R.K. STIM and Orai proteins as novel targets for cancer therapy. A Review in the Theme: Cell and Molecular Processes in Cancer Metastasis. Am. J. Physiol. Physiol. 2015, 309, C457-C469. [CrossRef] [PubMed]

110. Feng, M.; Grice, D.M.; Faddy, H.M.; Nguyen, N.; Leitch, S.; Wang, Y.; Muend, S.; Kenny, P.A.; Sukumar, S.; Roberts-Thomson, S.J.; et al. Store-Independent Activation of Orai1 by SPCA2 in Mammary Tumors. Cell 2010, 143, 84-98. [CrossRef] [PubMed]

111. Srivats, S.; Balasuriya, D.; Pasche, M.; Vistal, G.; Edwardson, J.M.; Taylor, C.; Murrell-Lagnado, R.D. Sigma1 receptors inhibit store-operated $\mathrm{Ca}^{2+}$ entry by attenuating coupling of STIM1 to Orai1. J. Cell Biol. 2016, 213, 65-79. [CrossRef]

112. Derler, I.; Jardin, I.; Stathopulos, P.B.; Muik, M.; Fahrner, M.; Zayats, V.; Pandey, S.K.; Poteser, M.; Lackner, B.; Absolonova, M.; et al. Cholesterol modulates Orai1 channel function. Sci. Signal. 2016, 9, ra10. [CrossRef]

113. Bohórquez-Hernández, A.; Gratton, E.; Pacheco, J.; Asanov, A.; Vaca, L. Cholesterol modulates the cellular localization of Orai1 channels and its disposition among membrane domains. Biochim. Biophys. Acta (BBA) Mol. Cell Biol. Lipids 2017, 1862, 1481-1490. [CrossRef] [PubMed]

114. Pacheco, J.; Dominguez, L.; Hernandez, A.B.; Asanov, A.; Vaca, L. A cholesterol-binding domain in STIM1 modulates STIM1-Orai1 physical and functional interactions. Sci. Rep. 2016, 6, 29634. [CrossRef] [PubMed]

115. Absi, M.; Burnham, M.P.; Weston, A.H.; Harno, E.; Rogers, M.; Edwards, G. Effects of methyl $\beta$-cyclodextrin on EDHF responses in pig and rat arteries; association between SKCachannels and caveolin-rich domains. Br. J. Pharmacol. 2007, 151, 332-340. [CrossRef] [PubMed] 